INTER VIVOS TRANSFERS AND

INTENDED BEQUESTS

\author{
Kathleen McGarry
}

Working Paper 6345 
NBER WORKING PAPER SERIES

\title{
INTER VIVOS TRANSFERS AND INTENDED BEQUESTS
}

\author{
Kathleen McGarry
}

Working Paper 6345

http://www.nber.org/papers/w6345

\section{NATIONAL BUREAU OF ECONOMIC RESEARCH 1050 Massachusetts Avenue \\ Cambridge, MA 02138 \\ December 1997}

I am grateful to Michael Hurd for many valuable discussions and to Donald Cox, Audrey Light, and Duncan Thomas for their helpful suggestions. I also received useful comments from Trudy Cameron, Wei-Yin Hu, Jean-Laurent Rosenthal, Kenneth Sokoloff and the seminar participants at the RAND/UCLA Labor and Population Workshop. Many thanks to Julie Zissimopoulos for research assistance. Financial support from the Brookdale Foundation and additional funding from the National Institute on Aging Fellowship through grant number T32-AG00186 to the NBER is gratefully acknowledged. Any opinions expressed are those of the author and not those of the National Bureau of Economic Research.

(C) 1997 by Kathleen McGarry. All rights reserved. Short sections of text, not to exceed two paragraphs, may be quoted without explicit permission provided that full credit, including $\mathbb{C}$ notice,
is given to the source. 
Inter vivos Transfers and Intended Bequests

Kathleen McGarry

NBER Working Paper No. 6345

December 1997

\begin{abstract}
Empirical work on intergenerational transfers has focused on distinguishing between altruistic and exchange motivated behavior. However, these two models are unable to explain the strong tendency for estates to be divided equally across children, while inter vivos transfers are made unequally. This paper presents a new framework for analyzing transfers from parents to children that is more consistent with observed behavior than are the altruistic and exchange models alone. In particular the model developed here allows for differing behavior with respect to inter vivos transfers and bequests due to uncertainty about the recipient's permanent income. The empirical work uses data from the Health and Retirement Survey and the Asset and Health Dynamics Survey. The patterns observed in these data are consistent with earlier findings that inter vivos transfers go disproportionately to less well-off children, while bequests are divided equally across children. Further, the results support the prediction of the model in that differences in inter vivos transfers arise from differences in current income, while bequests are unequal when the children's permanent incomes are different.
\end{abstract}

Kathleen McGarry

Department of Economics

University of California, Los Angeles

405 Hilgard Avenue

Los Angeles, CA 90095-1477

and NBER

mcgarry@ucla.edu 


\section{Introduction}

Every year an enormous amount of resources is transferred between generations. Government programs, such as Social Security, Medicare, and public education, comprise a large fraction of these intergenerational transfers. However, much money also flows through private institutions including churches, private charities and families. In this paper I focus on a subset of private transferstransfers from parents to their adult children. The volume of such transfers is large. The most recent estimates place the annual value of inter vivos transfers to adult children at approximately 33 billion in 1986 dollars, and the yearly value of bequests (not necessarily to children) at approximately 105 billion dollars (Gale and Scholz, 1994). ${ }^{1}$ Although these flows have received less attention than government assistance programs, they are much larger. For example, in comparison with the above mentioned figures on inter vivos transfers, in 1986 yearly spending on the Aid to Families with Dependent Children Program (AFDC) was just over 16 billion dollars and total payments in the Supplemental Security Income Program (SSI) were 12 billion.

Much of the current literature on transfers seeks to explain the motivation behind these intergenerational linkages, and in doing so, to understand their distributional effects (c.f. Barro 1974; Cox 1987; Behrman, Pollak, and Taubman, 1990; Altonji, Hayashi and Kotlikoff 1992). If for example, families transfer resources to improve the well-being of poorer members, then government transfer programs that also target these poor individuals may simply replace or crowd out familial assistance. Conversely, if transfers are payments made in exchange for services-a parent compensating a child for providing home health care, for example-then government programs will have less of an impact on familial behavior. ${ }^{2}$

Despite a substantial amount of research, a consensus has not yet been reached about the importance of alternative models. Bernheim et al. (1985) propose an exchange model in which the promise of a bequest serves to motivate children to act according to the parent's wishes. In support of the model their empirical results indicate a positive relationship between the parent's bequeathable wealth and the attention she receives from her children. However, studies of probate

\footnotetext{
${ }^{1}$ Earlier figures from Kurz (1984) point to an even larger yearly flow of inter vivos transfers at approximately $\$ 95$ billion in 1986 dollars, but only $\$ 14$ billion in bequests.

${ }^{2}$ Other models of transfer behavior currently discussed in the literature suggest that transfers may be made for the purchase of specific items (the paternalistic model), or that the donor receives utility from the act of giving (the
warm glow model).
} 
records (Menchik 1980,1988) and reports of existing wills (Dunn and Phillips 1997) have repeatedly found that very few parents bequeath unequal amounts to their children. Using IRS records, Wilhelm (1996) provides a detailed examination of the division of estates across children and finds that estates are divided approximately equally among children close to 90 of the time. However, the question of why bequests are made equally has not been satisfactorily addressed. Wilhelm models the phenomenon by using a constant fixed cost, $\kappa$, to represent the disutility obtained from unequal division. Rather than explaining the decision to make equal bequests, this specification simply begs the question as to the origin of $\kappa$.

In contrast to identical bequests, dissimilar transfers are often observed with respect to inter vivos gifts. In some of the first detailed empirical work done on inter vivos transfers, Cox (1987) and Cox and Rank (1990) find evidence that parents give more to better-off children, behavior that would reinforce economic differences between siblings. However, more recent work has found that less well-off children benefit disproportionately from these transfers (Altonji, Hayashi, and Kotlikoff, 1994; Dunn 1994; McGarry and Schoeni, 1995, 1997).

Because of data limitations, the empirical literature has looked separately at inter vivos transfers and bequests while assuming that the same behavioral model is driving both types of transfers. However, evidence from the empirical investigations mentioned above suggests that the behaviors differ. In this paper I propose an expanded model of transfer behavior. The model treats the giving of inter vivos transfers and bequests as part of the same decision process, but yields different predictions about the expected patterns for the two types of transfers. In the model parents are assumed to hold a prior beliefs about the level of consumption attainable by their children. This prior is a function of family-specific tastes and abilities, as well as child-specific characteristics such as sex and schooling. Parents use observations on the child's current income to update this prior, and the updated level of expected consumption serves as a basis for the decision on transfers. Inter vivos transfers are based on expected consumption in the current period while bequests are based on expected future consumption. If an observation on current income is more informative about current consumption than it is about future consumption, inter vivos transfers will be more strongly correlated with the current income of the child than are bequests. In the limit, differences in current income will have no effect on bequests.

The paper uses two newly released data sets, the Health and Retirement Survey (HRS), and the 
Asset and Health Dynamics Survey (AHEAD), to test the predictions of the model. These surveys provide more detailed information on the prevalence and magnitude of inter vivos transfers, and on the characteristics of the potential donors and recipients of these transfers, than has been available in the past. Furthermore, AHEAD collects information on expected bequests and can therefore be used to study that aspect of transfer behavior. In contrast to previous studies of bequests based on estates filing tax returns, AHEAD is a nationally representative sample of individuals age 70 and over and therefore provides a description of bequests among the entire population.

The data reveal a number of interesting patterns with respect to the timing and distribution of transfers. Consistent with the model, and with previous studies, I find that inter vivos gifts are compensatory, with larger transfers flowing to less well-off children, while bequests are typically made equally to all children. Furthermore, the probability of leaving a bequest is positively related to the current income of children, but negatively related to permanent income. The results also demonstrate that parents respond strongly to tax incentives and use transfer mechanisms that reduce the tax burden eventually facing the estate.

\section{Theoretical Framework}

Consider a two-period model in which a parent dies at the end of the first period while the child lives to the second period. The parent has three uses for her stock of wealth: her own consumption, transfers to the child in the current period (inter vivos transfers), and bequests left to the child. Parents are altruistic towards their children in that the child's utility is an argument in the utility function of his parent (Barro 1974, Becker 1974). I assume that the child's consumption is a function of both permanent and transitory income and that the child cannot borrow against expected bequests. The parent observes the child's income in the current period and makes a decision about how much to transfer immediately, through inter vivos transfers, and how much to transfer in the second period through bequests. If current income provides more information about current consumption than it does about future consumption, inter vivos transfers will be more highly correlated with the child's current income than will bequests. 


\subsection{Outline of formal model}

Following Yaari (1965) I assume that the parent's utility function is additively separable and that parents maximize

$$
U_{p}=U\left(c_{p}, V\left(c_{k}\right)\right)+B\left(c_{f}\right)
$$

where $c_{p}$ and $c_{k}$ are current consumption of the parent and child, and $c_{f}$ is the child's level of consumption after the parent dies. ${ }^{3}$ Thus inter vivos transfers and bequests need not have identical effects on the parent's utility function. The parental budget constraint is

$$
w_{p}=c_{p}+t+b
$$

where $w_{p}$ is the wealth of the parent, $t$ represents inter vivos transfers to the child, and $b$ is bequests. The first derivatives of $U,\left(U_{1}\right.$ and $\left.U_{2}\right)$ are positive, and the second derivatives $\left(U_{11}\right.$ and $\left.U_{22}\right)$ are negative. I also assume that the cross partial derivatives are non-negative $\left(U_{12}=U_{21} \geq 0\right) .{ }^{4}$ Similarly, the first derivatives of $V$ and $B$ are positive and the second derivatives negative $\left(V^{\prime}>\right.$ $0, B^{\prime \prime}>0, V^{\prime \prime}<0$, and $B^{\prime \prime}<0$.)

It is typically found that consumption depends both on permanent income and current income. In the terminology used in the consumption literature is that consumption is "excessively sensitive" to current income. ${ }^{5}$ The most frequently cited explanations for this excess sensitivity are the presence of liquidity constraints and precautionary savings. I model the child's consumption in each period as a function of permanent income $y_{p}$ and transitory income in the particular period $y_{t_{1}}$ and $y_{t_{2}}$. Thus

$$
\begin{aligned}
& c_{k}=\alpha y_{t_{1}}+\gamma y_{p}+\xi_{k} \\
& c_{f}=\alpha y_{t_{2}}+\gamma y_{p}+\xi_{f}
\end{aligned}
$$

where $\alpha$ and $\gamma$ are the marginal propensities to consume out of transitory income and permanent income, and $E\left[\xi_{1}\right]=0 .{ }^{6}$ Parents can increase the child's first period consumption by making an

\footnotetext{
${ }^{3}$ The notation $B\left(c_{f}\right)$ is used for simplicity. It should not be construed as implying that the parent cares about the particular consumption bundle as in the paternalistic model, but rather that the parent cares about the child's future utility in that $B\left(V\left(c_{f}\right)\right)$ and $V$ is subsumed in $B$.

'The alternative assumption, that the increase in the parent's utility for an increase in own consumption is lower the greater is the child's consumption ( $U_{12}=U_{21}<0$ ) is unlikely to describe accurately parental preferences.

${ }^{5}$ For empirical evidence that consumption is not based solely on permanent income see Hall and Mishkin (1982). Deaton (1992) and Browning and Lusardi (1996) provide detailed summaries and discussions of this literature.

${ }^{6}$ This specification can be written equivalently in terms of current income $y_{k}$, and $y_{p}$ as $\alpha y_{k}+(\gamma-\alpha) y_{p}$.
} 
inter vivos transfer $t$ and can increase future consumption through bequests $b .^{7}$

One would not expect permanent income to be predicted perfectly, especially by the parent. The approach I take here is to assume that parents hold a prior belief about $y_{p}$ such that

$$
y_{p} \sim N\left(\mu+X \beta, \sigma^{2}\right)
$$

$\mu$ represents a constant family specific component and $X$ represents characteristics of the child such as age, schooling, and occupation, that are observed by the parent and correlated with permanent income. ${ }^{8} \sigma^{2}$ is assumed to be known by the parent. In the absence of information $X$, a parent assumes that her child will have permanent income $\mu$. Thus, prior to the information in $X$ being revealed, a parent with more than one child will expect all children to have the same level of permanent income. The importance of the child-specific characteristics in altering this perception depends on the weights $(\beta)$ attached to the variables, relative to the magnitude of $\mu .^{9}$

In the current period a parent observes the child's income $y_{k}$ and uses the information in $y_{k}$ to update her belief about $y_{p}$. Current income is related to permanent income through the model

$$
\begin{gathered}
y_{k}=y_{p}+y_{t_{1}} \\
y_{t} \sim N\left(0, \tau^{2}\right), E\left(y_{t} \mid y_{p}\right)=0, \text { and } y_{t} \text { are } i i d .
\end{gathered}
$$

Using Bayes' Rule

$$
f\left(y_{p} \mid y_{k}\right) \propto g\left(y_{k} \mid y_{p}\right) h\left(y_{p}\right)
$$

where $h\left(y_{p}\right)$ is $N\left(\mu+X \beta, \sigma^{2}\right)$, this relationship implies that

$$
f\left(y_{p} \mid y_{k}\right) \sim N\left(\frac{\tau^{2}}{\tau^{2}+\sigma^{2}}(\mu+X \beta)+\frac{\sigma^{2}}{\tau^{2}+\sigma^{2}} y_{k}, \frac{\tau^{2} \sigma^{2}}{\tau^{2}+\sigma^{2}}\right) .
$$

The ratio of the variances $\sigma^{2} / \tau^{2}$ (with both $\sigma^{2}$ and $\tau^{2}$ known by the parents) determines the relative importance of the parent's prior beliefs and the observation on income. The larger is $\sigma^{2}$ relative to

\footnotetext{
${ }^{7}$ In deriving the comparative statics I assume that transfers are treated as transitory income in the child's consumption function. The results are qualitatively unchanged if $I$ assume that transfers are consumed entirely in the period they are received.

${ }^{8}$ Here it does not matter whether permanent income is defined as the annuity value of lifetime resources or whether it evolves over a lifetime. With the information available at a given time, the parent's expectation of the child's permanent income for the current period will be the same as her expectation of the child's permanent income in the future.

${ }^{9}$ See Altonji and Dunn (1991), Solon et al. (1991), and Lillard and Kilburn (1996) for estimates of income correlations across siblings.
} 
$\tau^{2}$, the greater the weight the parent places on current income in determining $y_{p}$, relative to child characteristics and the constant $\mu$.

Using the relationship $y_{k}=y_{p}+y_{t_{1}}$, the conditional expectation of transitory income in the first period, $y_{t_{1}}$, given $y_{k}$, can be written as

$$
E\left[y_{t_{1}} \mid y_{k}\right]=\left(\frac{\tau^{2}}{\tau^{2}+\sigma^{2}}\right)\left(y_{k}-[\mu+X \beta]\right) .
$$

Using the relationship $c_{k}=\alpha y_{t_{1}}+\gamma y_{p}+\xi_{f}$,

$$
E\left[c_{k} \mid y_{k}\right]=\left(\frac{\tau^{2}(\gamma-\alpha)}{\tau^{2}+\sigma^{2}}\right)(\mu+X \beta)+\left(\frac{\alpha \tau^{2}+\gamma \sigma^{2}}{\tau^{2}+\sigma^{2}}\right) y_{k} .
$$

When looking ahead to period 2, the parent's expectation of $y_{p}, E\left[y_{p} \mid y_{k}\right]$, is unchanged. However, the period one observation on income, $y_{k}$, provides no information about transitory income in period two (i.e. $E\left[y_{t_{2}} \mid y_{k}\right]=E\left[y_{t_{2}}\right]=0$ ), so that $E\left[c_{f} \mid y_{k}\right]$ depends only on the expected value of permanent income.

$$
E\left[c_{f} \mid y_{k}\right]=\left(\frac{\gamma \tau^{2}}{\tau^{2}+\sigma^{2}}\right)(\mu+X \beta)+\left(\frac{\gamma \sigma^{2}}{\tau^{2}+\sigma^{2}}\right) y_{k} .
$$

Comparing the expected value of period one consumption (1) with the expected value of period two consumption (2) it is apparent that (1) unambiguously puts more weight on $y_{k}$ than does (2), with the difference equal to

$$
\left(\frac{\alpha \tau^{2}}{\tau^{2}+\sigma^{2}}\right)\left(y_{k}-[\mu+X \beta]\right) .
$$

In other words, the parent weights current income more heavily in deciding on the amount to transfer in the current period, than when deciding on the amount to bequeath. As the parent's prior belief about $y_{p}$ becomes unimportant relative to observed income (i.e. as $\sigma^{2} / \tau^{2}$ becomes large), $\left(\frac{\sigma^{2}}{\tau^{2}+\sigma^{2}}\right) \rightarrow 1$, and $\left(\frac{\tau^{2}}{\tau^{2}+\sigma^{2}}\right) \rightarrow 0$ and all the weight is put on $y_{k}$. Alternatively, the better the prior predicts permanent income, the smaller is $\sigma^{2} / \tau^{2}$, and the less weight parents will give to observed income in updating their prior. In the limit $\left(\frac{\tau^{2}}{\tau^{2}+\sigma^{2}}\right) \rightarrow 1$ and $\left(\frac{\sigma^{2}}{\tau^{2}+\sigma^{2}}\right) \rightarrow 0$, and $y_{k}$ will be used to determine transitory income only, $y_{p}$ (and therefore bequests) will depend solely on $\mu+X \beta$.

Assuming certainty equivalence of the child's consumption, the parent chooses $t$ and $b$ to maximize the utility function

$$
U=U\left(c_{p}, V\left(E\left[c_{k} \mid y_{k}\right]\right)\right)+B\left(E\left[c_{f} \mid y_{k}\right]\right)
$$

subject to the budget constraint

$$
w_{p}=c_{p}+t+b .
$$


For multi-child families the specification of parental utility follows straightforwardly. For simplicity suppose there are two children in the family. Denoting the values for child $j$ with appropriate superscripts, the utility function becomes

$$
U_{p}=U\left(c_{p}, V\left(c_{k}^{1}\right), V\left(c_{k}^{2}\right)\right)+B\left(c_{f}^{1}, c_{f}^{2}\right)
$$

\subsection{Implications}

The specification of the utility function in this model differs from the standard altruism model in that the child's current income affects both the consumption of the child in the current period, and the parent's expectation of her child's future consumption. Thus, an increase in the child's income decreases both the marginal utility of inter vivos transfers and the marginal utility of a bequest. The resulting change in the transfers made by the parents is, however, ambiguous, and as shown in the examples below, depends on the assumptions made about the shape of the indifference curves and the relative magnitudes of $\sigma^{2}$ and $\tau^{2}$.

The comparative statics for the standard altruism model as developed in Cox (1987) imply that if the parent's income increases by one dollar and the child's income decreases by one dollar, transfers will increase by one dollar. Or, in the notation of this paper,

$$
\frac{\partial t}{\partial w_{p}}-\frac{\partial t}{\partial y_{k}}=1
$$

Empirical tests of this prediction have all led to rejection of the altruism hypothesis (Altonji et al., 1994; McGarry and Schoeni, 1995). In the current model, changes in the observed income of the child affect both inter vivos transfers and bequests, and this strict relationship no longer holds.

The comparative statics are presented in full in Appendix 1. Here I discuss the outcomes for two specifications that are special cases of the above model.

Example I: Parents observe the consumption of an inter vivos transfer but do not observe the consumption of a bequest. Hence it is reasonable to assume that the mechanisms through which the parent receives utility differ for the two types of transfers. One might well imagine that because the consumption of a bequest is never directly observed, the utility a parent receives from making a bequest depends on the amount of the bequest alone, rather than from the increase in the child's expected utility. In this case, bequests provide utility through a "warm glow" (Andreoni, 1989) 
and the model can be formally specified as

$$
U_{p}=U\left(c_{p}, V\left(c_{k}\right)\right)+B(b)
$$

With decreasing marginal utility, bequests will be divided equally among children while inter vivos transfers will continue to be compensatory. This specification is analogous to the "separable earnings/bequest model" proposed by Behrman, Pollak, and Taubman (1990). ${ }^{10}$

The specification in (3) is a special case of the Bayesian model outlined above. If current income provides little information about permanent income, the parent puts less weight on the observed value of current income in updating her belief about future consumption. In the limit, $\left(\frac{\tau^{2}}{\tau^{2}+\sigma^{2}}\right) \rightarrow 1$, and $\left(\frac{\sigma^{2}}{\tau^{2}+\sigma^{2}}\right) \rightarrow 0$, current income does not affect the parent's expectation of the child's permanent income, and the marginal utility of a bequest is therefore unaffected by current income. Here bequests will differ across children through differences in the observable characteristics of the child $(X \beta)$ alone. If in addition, $X \beta$ is small relative to $\mu$, then bequests will be approximately equal. When $\left(\frac{\tau^{2}}{\tau^{2}+\sigma^{2}}\right) \rightarrow 1$, and $\left(\frac{\sigma^{2}}{\tau^{2}+\sigma^{2}}\right) \rightarrow 0$, the comparative statics are unambiguous. $\frac{\partial t}{\partial w_{p}}>0, \frac{\partial b}{\partial w_{p}}>0, \frac{\partial t}{\partial y_{k}}<0$, and through the budget constraint $\frac{\partial b}{\partial y_{k}}>0$. The result from the standard altruism model that $\frac{\partial t}{\partial w_{p}}-\frac{\partial t}{\partial y_{k}}=1$ also holds.

Example II: An important feature of the general model is that it allows the utility the parent receives from the child's consumption in the future period, $B(\cdot)$, to differ from the utility she receives from current consumption. Imposing additional structure on these components of the utility function allows one to sign the derivatives. Consider restrictions on the second derivatives such that the derivative of the parent's marginal utility with respect to the child's current consumption is equal to the derivative of her marginal utility with respect to bequests. In other words,

$$
U_{22}\left(V^{\prime}\right)^{2}+U_{2}\left(V^{\prime \prime}\right)=B^{\prime \prime}
$$

Assume also that $U_{12}=U_{21}=0$. With these rather mild assumptions $\frac{\partial t}{\partial w_{p}}>0, \frac{\partial b}{\partial w_{p}}>0$, and $\frac{\partial t}{\partial y_{k}}<0$ as is typical in altruism models. However, $\frac{\partial b}{\partial y_{k}}$ cannot be signed without imposing further restrictions.

\footnotetext{
${ }^{10}$ In the Behrman, Pollak, and Taubman model parents transfer resources while alive to pay for schooling of the child and thereby increase the child's earnings (utility in the current model) and also make equal bequests.
} 
As an example, suppose that the utility function of the parent is highly curved in own consumption (i.e. $U_{11}$ is large in absolute value) so that the marginal utility falls quickly as consumption increases beyond the optimal point. Imagine, for example, that the parent has become "set in her ways" and is content with her current level of consumption. Suppose further that relative to her own consumption, the function $B(\cdot)$ has a very small curvature, and thus small movements around the optimal point are associated with small changes in marginal utility. Now consider the following scenario. The child's income increases, corresponding to decreases in the marginal utility of $t$ and the marginal utility of $b$. It can be shown that in this model the decrease in the marginal utility of $t$ is larger than the decrease in the marginal utility of $b$. To equalize the marginal utility across arguments, the parent will shift resources to her own consumption, shifting more away from $t$ than from $b$. If $U_{11}$ is large, then only a small increase in consumption is needed to decrease in the marginal utility of consumption sufficiently to equate it with the marginal utility from the child's consumption. If the initial change in the marginal utility of $b$ was small ( $B^{\prime \prime}$ small in absolute value), then in order to equate the marginal utility of $b$ to the marginal utility of $t$ and of $c_{p}$, it will be necessary to increase bequests. Thus, the derivative $\partial b / \partial y_{k}$ can positive. Regardless of the sign of $\frac{\partial b}{\partial y}$, the quantity $\left(\frac{\partial t}{\partial w_{p}}-\frac{\partial t}{\partial y_{k}}\right)$ does not necessarily equal one.

\subsection{Extensions of Model}

Here I discuss two extensions of the model. First, I incorporate an uncertain date of death, and second I discuss the impact of estate and gift taxes on transfer behavior.

\subsubsection{Uncertainty}

In analyzing bequests researchers have long recognized that some bequests may be accidental, due to an uncertain length of life (Hurd 1987). If a parent holds wealth to finance future consumption and dies earlier than she had expected, her remaining wealth will be left as a bequest. The oneperiod model presented above contains no such uncertainty. Consider an extension of the model to include an uncertain length of life. Suppose there are two periods and the parent survives to the second period with known probability $p$, where $p$ is a function of health, sex, race, etc. If the parent survives to period two, she dies with certainty at the end of that period. Children survive 
their parents. In the first period the parent uses her wealth both to finance her own consumption and to make inter vivos transfers. If the parent dies at the end of period one, her remaining wealth is bequeathed to the child. However, if the parent survives to period two, she must finance her own consumption and transfers in the second period from her remaining resources. The parent dies with certainty at the end of period two and all remaining wealth is bequeathed to the child. The parent therefore maximizes an expected utility function that is a weighted average of her utility if she lives for one period (with probability $1-p$ ) and her utility if she lives for two periods (with probability $p$ ). Here I illustrate the case with one child although additional children can be added straightforwardly as in the previous section. The subscripts denote the period (either 1 or 2 ).

$$
\begin{aligned}
E\left[U_{p}\right] & =(1-p)\left[U_{1}\left(c_{p_{1}}, V\left(c_{k_{1}}\right)\right)+B\left(c_{f_{1}}\right)\right]+p\left[U_{1}\left(c_{p_{1}}, V\left(c_{k_{1}}\right)\right)+U_{2}\left(c_{p_{2}}, V\left(c_{2}\right)\right)+B\left(c_{f_{2}}\right)\right] \\
& =U_{1}\left(c_{p_{1}}, V\left(c_{k_{1}}\right)\right)+(1-p) B\left(c_{f_{1}}\right)+p U_{2}\left(c_{p_{2}}, V\left(c_{k_{2}}\right)\right)+p B\left(c_{f_{2}}\right)
\end{aligned}
$$

$$
\begin{aligned}
\text { subject to } b_{1} & =w_{p}-c_{p_{1}}-t_{1} \\
\text { and } b_{2} & =w_{p}-c_{p_{1}}-t_{1}-c_{p_{2}}-t_{2}
\end{aligned}
$$

which can be rewritten as $b_{2}=b_{1}-c_{p_{2}}-t_{2}$.

$c_{f_{1}}$ and $c_{f_{2}}$ are the expected future income of the child with expectation taken at time 1 and time 2.

Given a standard utility function in which $U \rightarrow-\infty$ as $c_{p_{2}} \rightarrow 0, c_{p_{2}}$ will be greater than zero, and therefore $b_{1}>0$. Thus, even if desired bequests are zero, accidental bequests $\left(b_{1}\right)$ will be greater than zero if the parent dies at the end of period 1. The greater is $p$ the more weight put on consumption in the second period, the greater will be $c_{p_{2}}$, and the greater will be $b_{1}$ should the parent die in period one. Second, even if the parent chooses $b_{2}=0$, with two or more children (and a non-degenerative function $B$ ) her utility will depend on the distribution of $b_{1}$, and she will therefore still have an incentive to ensure the optimal division of the estate even though the bequest is unintentional.

\subsubsection{Tax incentives}

In the above model, a parent may choose to transfer resources while she is alive and/or she may transfer resources through a bequest. A potential cost associated with bequeathing a large amount 
of wealth is that for large estates (over $\$ 600,000$ ) the inheritance may be reduced substantially by estate taxes. ${ }^{11}$ Inter vivos transfers above $\$ 10,000$ per recipient per year are also subject to tax, while transfers below $\$ 10,000$ are not. A parent who intends to leave a bequest, and who expects her estate to be subject to estate taxes, may begin to transfer bequests before her death, making transfers of $\$ 10,000$ per year to each child and reducing the amount of the eventual estate that will be subject to tax.

One would expect the prevalence of these $\$ 10,000$ transfers to increase as the number of remaining years the parent expects to live decreases. As a parent ages there are fewer years over which to make tax driven transfers or to spend-down assets, and less uncertainty about the potential need for resources. It is also likely that a parent who does not expect to live much longer would be more likely to have done some estate planning and thus would be more familiar with the tax code than would a younger parent. In the context of the simple two-period model, a parent knows with certainty in the second period what bequests will be and can therefore act to reduce the $\operatorname{tax}$ obligations of the estate. Tax incentives will therefore induce wealthy parents to make inter vivos gifts with a portion of intended bequests. These "early bequests" will be made in sums of $\$ 10,000$ per child for a single parent, and $\$ 20,000$ for a couple. Thus as a parent ages (moves to period 2 of the model) there will be a greater probability that she will make "bequest based" transfers which will be identical across children. ${ }^{12}$

To represent the tax environment accurately both bequests and inter vivos transfers need to be reduced by the applicable tax. Thus if total bequests $\left(b_{1}\right.$ or $\left.b_{2}\right)$ are greater than $\$ 600,000$ and $\delta_{1}$ is the appropriate estate tax rate, the actual transfer is $b_{i}-\max \left[b_{i}-600000,0\right] *\left(\delta_{1}\right)$, where $i=1,2$ denotes the period of time. Similarly, inter vivos gifts of greater than $\$ 10,000$ to a particular individual, are reduced by tax rate $\delta_{2}$ so that the transfer $t_{I}^{j}$ becomes $t_{I}^{j}-\max \left[t_{I}^{j}-10000,0\right] *\left(\delta_{2}\right)$ in period $I, I=1,2$, for child $j, j=1,2 \ldots{ }^{13}$ In order to transfer a given amount, a parent must

\footnotetext{
${ }^{11}$ In 1992 and 1993 when the HRS and AHEAD data were collected, the tax rate for the first dollar over $\$ 600,000$ was 37 percent, and marginal rates increased from there to 55 percent (IRS publication no. 448). Most states also impose their own estate taxes, but for the majority of states (28 in 1992) the effect is to reduce the revenue going to the federal government with no change in the tax burden on the estate. Seventeen states impose additional taxes on the beneficiaries rather than on the estates themselves. Transfers to a spouse are exempt from the $\$ 600,000$ limit.

${ }^{12}$ Parents may also avoid estate taxes through the use of trusts. Trusts incur administrative costs which reduce the amount eventually received by the children. Thus even parents who establish a trust have an incentive first to make "costless" transfers of $\$ 10,000$ per child.

${ }^{13}$ Even this formulation is somewhat of a simplification. As the tax law is written, each individual has a lifetime tax exemption of $\$ 600,000$ in addition to the $\$ 10,000$ per person, per year, exemption (this $\$ 10,000$ tax free gift cannot be carried over if it is not used). Thus, transfers greater than $\$ 10,000$ do not immediately incur a tax, but are
} 
spend more than the amount of the transfer because of the existence of the tax.

\section{Empirical Analysis}

To test the model I focus on the effects of the child's income on the transfer behavior of the parent. The model predicts that a child's current income will be more strongly (negatively) related to inter vivos transfers than to bequests, while permanent income will be more strongly related to bequests. In the two special cases described in section 2.2 (if current income is uninformative in the expectation of permanent income, or if certain restrictions are placed on the second derivatives of the utility functions) bequests may be positively related to current income. Observations on the current income of children are available in my data and are used directly in the analysis. I use schooling as a proxy for the permanent income of the child. Liquidity constraints will make some children's consumption more sensitive to current income than would otherwise be the case. Thus factors that proxy the existence of liquidity constraints ought to increase inter vivos transfers but have a weaker relationship to bequests. I use age, home ownership and marital status as proxies.

A secondary focus of the analysis is the effect of taxes on transfer behavior. The existence of estate taxes for the very wealthy suggests that their behavior may differ from that of less wealthy parents. In particular, wealthy parents may endeavor to "spend down" their resources by making large inter vivos transfers. Gifts over $\$ 10,000$ are taxable, so the speed with which a wealthy parent can divest herself of assets is limited. For these families one would expect to see equal inter vivos transfers in amounts of $\$ 10,000$, whereas such behavior would be unlikely for the less wealthy.

In the analyses below I ask which parents make inter vivos transfers and which intend to leave a bequest as functions of the characteristics of their children and the patential for taxation of the estate. Because previous studies have shown strong differences in the likelihood of equal inter vivos transfers across siblings and equal bequests, I also examine the probability of equal treatment in each case. If the current incomes of siblings differ, but their permanent incomes are similar, one would expect unequal inter vivos transfers, and potentially equal bequests.

Following this parent-level analysis, I focus on the children themselves and look within families

deducted from the value of assets which can eventually be bequeathed tax free. Furthermore, by dividing transfers between the various members of a child's household-for example a son, his wife and his children-and transferring $\$ 10,000$ to each, parents can potentially transfer a much greater amount of wealth in each year than is indicated by the $\$ 10,000$ listed in the tax code. 
to ask which children are the recipients of transfers, and in the case of inter vivos transfers, the amount received by each child. ${ }^{14}$ By estimating family fixed effect models I am able to control for unobserved differences across families in the parents' generosity towards their children. If these differences are correlated with the observable characteristics of the children, the ordinary regression estimates will be biased.

One difficulty with addressing transfer behavior empirically is that inter vivos transfers are observed for only a short segment of the child's life. One might imagine that parents make inter vivos transfers in response to particular events in the child's life, a graduation or wedding for example, and equalize lifetime transfers to children regardless of their permanent incomes. In the theoretical analysis this problem is avoided by having a single period in which parents can make inter vivos gifts. In the empirical work I control for this possibility as much as possible by including indicators such as whether the child is still in school, is married, or has children of his own. However, without an extremely long panel data set it is impossible to assess the importance of such behavior.

\subsection{The Data}

The data requirements of this analysis are extensive. One needs information on both inter vivos transfers and bequests, on the characteristics of the children (the potential recipients) and on the characteristics of the parents (the potential donors). Because there likely exist unobserved measures of generosity or affection across families it would be useful to be able to control for family effects and analyze differences in transfers to children within a family.

The Health and Retirement Survey (HRS) and the Asset and Health Dynamics Survey (AHEAD) provide a unique opportunity to address these issues. The HRS samples individuals born from 1931 to 1941 , and AHEAD samples an older cohort born in 1923 or earlier. Both surveys also interview spouses of sample members, even if the spouse's age is outside the targeted age range. The first interviews for the two surveys were in 1992 and 1993 respectively. When appropriately weighted, both the HRS and AHEAD are representative of the non-institutional population for the respective target cohort. ${ }^{15}$ Because the surveys are conducted jointly, the survey instruments themselves share many of the same questions and are easily compared. The discussion here focuses on the information useful in a study of transfer behavior. More general descriptions of the two surveys are

\footnotetext{
${ }^{14}$ Amounts of intended bequests are not available in the data.

${ }^{15}$ Weighting is necessary because individuals in heavily black and Hispanic areas were over-sampled in both surveys.
} 
available in Juster and Suzman (1995) and Soldo et al. (1997).

HRS and AHEAD provide a unique opportunity to study transfer behavior. Transfers to children are mentioned explicitly, ${ }^{16}$ with respondents asked to report transfers of $\$ 500$ or more made to each child in the past year. There is also a substantial amount of information available for both the respondents and their children. Past studies (Cox, 1987; Cox and Rank, 1992) often lacked information on one of the parties involved in the transfer, leading to an omitted variables problem and potentially biased estimates. The surveys collect information (as reported by the parent) on the child's age, household income, schooling level, employment status, marital status, number of own children (grandchildren to the respondent), and home ownership. This detailed information makes it possible to identify the economic status of each (potential) recipient both on an absolute level, and relative to his siblings.

Along with the questions about inter vivos gifts, AHEAD asks respondents about their intentions with respect to bequests: Whether they have a will, whether they expect to leave a bequest, the probability the bequest is above some threshold, whether their children are listed as heirs if there is a will, and whether they provide equally for all children in their will. These questions have not been asked of other nationally representative samples, and when linked with income and wealth data, these data have the potential for greatly improving our knowledge of inheritances.

\subsubsection{Sample population}

In the HRS the full sample consists of 7703 households. Reducing the sample to households with non-coresident children age 18 and over reduces the sample to 6181 families with 18,874 noncoresident adult children. ${ }^{17}$ The initial sample in AHEAD consists of 6051 households leaving a

\footnotetext{
${ }^{16}$ Most surveys use a more general question asking about assistance to anyone outside the household. HRS and AHEAD include both a general transfer question and specific questions about transfers to children. Comparisons with other data sets suggest that the detailed probing captures more transfers than broader questioning.

${ }^{17}$ For the analyses in this paper I select only those children who are age 18 or older and who do not live with the respondent. Transfers made to children under 18 are likely to be legally required payments such as child support and will therefore differ from the altruistic or exchange based transfers made to older children. I exclude co-resident children because of the difficulty of quantifying the value of shared food and housing. Certainly by providing room and board for an adult child a parent is making a substantial transfer. However, in neither data set do we know the value of this transfer or the amount which the child contributes to the household. In the AHEAD survey, parents are asked if their co-resident children contribute financially to the household, but they are not asked to provide an estimate of the amount of the contribution. No such questions are asked in the HRS. In the HRS approximately 16 percent of all children age 18 and over are residing with their parents. This figure includes those who are temporarily away at school. In AHEAD, only 7 percent of adult children reside with parents. Cash transfers to co-resident children are larger and more frequent than to non-coresident children (McGiarry and Schoeni, 1995).
} 
sample of 4835 households and 14,249 children after imposing the same restrictions as in the HRS.

In tables $1 \mathrm{a}$ and $1 \mathrm{~b}$, the means of the variables to be used in the analysis are presented separately for the HRS sample and for AHEAD. Table la reports the means of a family-based sample with one observation for each HRS or AHEAD family. The largest differences between the HRS and the AHEAD data are as expected. Both income and wealth are greater for the HRS households than for the AHEAD households, consistent with a lifecycle pattern in which assets are depleted during the nonworking (low income) years. Mean income for the younger cohort is $\$ 41,214$ compared to $\$ 21,790$ for the older group. The corresponding values for wealth are $\$ 248,377$ and $\$ 167,010$. This large difference in wealth exists despite the differential mortality by income and wealth which might be expected to mitigate the effects of dissavings. ${ }^{18}$ Due to differential mortality by sex, there are many more households with a male respondent in the HRS than in AHEAD. Similarly, the proportion of currently married households falls with age, from 70 percent in the HRS to 42 percent in AHEAD.

In both surveys respondents report self-assessed health status (excellent, very good, good, fair, and poor). Poor heal th may indicate that respondents face substantial medical expenses and are less able to make transfers. Unsurprisingly the younger HRS respondents are significantly less likely to report their health as poor. Each survey also asks respondents to report an estimated probability of surviving to a particular age. In the HRS respondents are asked about the probability of surviving to age 75. In AHEAD respondents are asked about the probability of surviving approximately 10 more years (the exact number of additional years differs across respondents because round numbers, such as age 85 or 90 , are chosen). The expected length of life will be relevant for the transfer behavior of those seeking to avoid estate taxes. Because the HRS respondents report significantly greater survival probabilities, they ought to be less concerned about spending down to avoid estate taxes than those in AHEAD.

In table $1 \mathrm{~b}$ I use a sample of children of HRS and AHEAD respondents. Each non-coresident adult child contributes one observation to the sample. Thus a family with three children age 18 and over will contribute three observations. HRS children are younger than AHEAD children with a

\footnotetext{
${ }^{18}$ Note that the HRS figures are in 1992 dollars while AHEAD figures are reported in 1993 dollars. The values are not in real terms in order to maintain consistency with the tax statutes which are written in nominal dollars (e.g. gifts above $\$ 10,000$ are taxed, estates over $\$ 600,000$ are taxed). The consumer price index increased by 3 percent from 1992 to 1993.
} 
mean age of 31 compared to 47 in AHEAD. The HRS children may therefore be more likely to face liquidity constraints, making current income a strong predictor of consumption. Consistent with the differences in age, HRS children are less well off financially in terms of home ownership and income, indicating either possible liquidity constraints or low current income relative to permanent income. Forty-six percent of HRS children own a home compared with 75 percent of AHEAD children. The two surveys used different breakpoints in recording categorical values for a child's income, ${ }^{19}$ so an exact comparison between surveys is not possible. The direction of the difference, however, is obvious. Approximately 50 percent of AHEAD children have incomes above $\$ 30,000$ while only 40 percent of HRS children have incomes above $\$ 25,000$. In the lower tail of the distribution, approximately 12 percent of AHEAD children have incomes below $\$ 20,000$ while 15 percent of HRS children have incomes below $\$ 10,000$. HRS children are also significantly less likely to be married or to have children of their own.

\subsubsection{Patterns of transfers}

The quantity of inter vivos transfers in each survey is large. As shown in table 2, 29 percent of households in the HRS made an inter vivos transfer of at least $\$ 500$ to at least one child and 13 percent of all children are reported to have been given a transfer. The numbers in AHEAD are surprisingly similar given the large differences in the age, income, and wealth, of the two samples. Mean transfers to each child (over all children receiving a positive amount) are $\$ 3013$ in HRS, and $\$ 4215$ in AHEAD. The difference between the median amounts is similar to the difference in means. ${ }^{20}$

An unusual feature of the AHEAD survey is the information obtained on expected bequests. Most earlier work examining the division of estates was based solely on data from estates that were large enough to have been required to file a tax return. AHEAD is a nationally representative

\footnotetext{
${ }^{19}$ In AHEAD in addition to the given categories of: less than $\$ 20,000, \$ 20,000-\$ 30,000, \$ 30,000-\$ 50,000$ and $\$ 50,000$ or more, respondents could also give a less specific answer by combining two intervals, for example, a respondent could answer that her child's income was less than $\$ 30,000$ if she did not know if it was greater than or less than $\$ 20,000$.

${ }^{20}$ Because the HRS and AHEAD surveys sample particular cohorts, it is not possible to inflate these results to approximate a flow of transfers for the entire population. However, applying the average of the HRS and AHEAD probabilities of a parental household (married couple or single individual) making a transfer to at least one child (27\%), and the mean amount given (\$5011), to the population age 50 and over (those making the majority of transfers), yields a total amount of inter vivos transfers by this age group of 52 billion dollars, a number within the range of results reported by Gale and Scholz (1994) and Kurz (1984).
} 
sample of the cohort born in 1923 or earlier and therefore provides a description of behavior across the wealth distribution. Respondents in AHEAD are asked to report, on a scale of $0-100$, the probability with which they expect to leave a bequest. As shown in table 3, the average reported probability (when scaled to lie between 0 and 1) among those respondents with at least one noncoresident adult child is $\mathbf{0 . 5 5}$, with a median value of $0.50 .{ }^{21}$ Furthermore, for the three-quarters of the sample with wills the inheritance will typically go, at least in part, to the children of the respondent; 87 percent (not shown) of those with a will name at least one child as a beneficiary. Estates are expected to be large. The mean probability of leaving more than $\$ 10,000$ is 0.57 , while the median is 0.75 . The probability of leaving more than $\$ 100,000$ is substantially lower. ${ }^{22}$

Whereas neither the altruism nor the exchange model predict that parents make equal transfers to their children, under certain assumptions the model presented here permits equal bequests. In AHEAD 83 percent of respondents who have a will, and who list children among the beneficiaries, report that their will treats all children "about equally" (not shown). ${ }^{23}$ This figure is quite close to the 88 percent making "approximately equal" bequests in Wilhelm's (1996) study based on data from the Internal Revenue Service. ${ }^{24}$ The similarity between actual probate data and the reported provisions of wills in AHEAD provides confidence in the reliability of the AHEAD data. ${ }^{25}$

In contrast to the prevalence of identical bequests, only 25.3 percent of the AHEAD families who made at least one inter vivos transfer in the past year (and who have more than one child), transferred equal amounts to all children. The number making equal inter vivos transfers in the HRS is even lower, with just 6.4 percent of families with two or more children transferring equal

\footnotetext{
${ }^{21}$ In the HRS respondents are asked whether or not they "expect to leave a sizeable inheritance". The possible answers are: yes, definitely; yes, probably; yes, possibly; probably not; no, definitely not. Of those respondents with non-coresident children, 43 percent gave one of the three affirmative responses. Because there is no way to define sizable, it is impossible to say whether these respondents are behaving differently from the AHEAD respondents.

${ }^{22}$ In Wilhelm's (1996) sample the mean amount of a bequest (per child) was close to $\$ 250,000$. The sample used in this paper and the Wilhelm sample are not comparable in this respect because the Wilhelm sample is based on estates filing an estate tax return and is therefore drawn from the uppermost tail of the wealth distribution.

${ }^{23}$ For individuals without a will, estates, by law, are usually divided equally among children if there is no surviving spouse. Individuals who are aware of this procedure, and who wish to leave identical bequests, may forego the expense (in terms of time, money and emotional energy) involved in writing a will, and leave it to the state to divide the inheritance equally.

"The definition of "about equal" in AHEAD is left to the respondent. Wilhelm follows Tomes (1988) in defining "approximately equal" as when "the difference between the maximum and minimum sibling inheritance is no more than one-quarter of the mean inheritance per child" (Wilhelm, p.880). Obviously amounts bequeathed are not yet available in AHEAD so a similar measure cannot be constructed. Earlier work by Menchik (1980, 1988) also found that few parents bequeathed unequal amounts to their children.

${ }^{25}$ Note that respondents are asked about the provisions of wills currently in existence, rather than about their intentions.
} 
amounts. ${ }^{26}$

Even among those making equal bequests, unequal inter vivos transfers are the norm. In simple cross tabulations using parents who both name a child in their will and make an inter vivos transfer, just 27 percent of those making equal bequests also made equal inter vivos transfers. However, this figure is substantially larger than the 8 percent making equal transfers among those with unequal bequests. I note however that these figures are based on a single cross-section. It may well be the case that over time differences in inter vivos transfers made to children offset each other and the total amounts given are less unequal than the amounts in a particular year. As future waves of the two surveys become available this possibility can be explored.

Because AHEAD respondents are older, they are more likely to be considering issues related to the distribution of their estate. The difference across surveys in the propensity to make equal transfers could therefore be indicative of tax avoidance behavior. One expects that wealthy parents will endeavor to reduce inheritance taxes, and thereby increase the total value of the resources transferred to their children, by making "early bequests." Because of the restriction on the amount of tax-free giving to each person in each year, wealthy parents would be expected to make transfers in round amounts equal to the $\$ 10,000$ limit. $^{27}$

In both surveys there is a significant difference in the transfer behavior of those with assets over $\$ 600,000$ and those with assets below this line. In the HRS, 15.5 percent of those with assets over $\$ 600,000$ make identical (positive) transfers to all children compared with 5.0 percent of less wealthy families. For the AHEAD sample (where estate planning is likely to be more prevalent) the numbers are much larger. Forty-three percent of those with assets of $\$ 600,000$ or greater make equal transfers to all children compared with 23 percent of those with fewer resources. ${ }^{28}$

\footnotetext{
${ }^{26}$ The portion of the sample transferring the same amount to all children is not sensitive to requiring exactly the same amounts. Respondents tend to report "round" numbers for the amount of the transfer and further rounding does not substantially increase the degree of equal transfers within families. The mean difference between the largest and smallest amounts given to children in a particular family, among families who make at least one transfer, is $\$ 2560$. The median difference is $\$ 1000$.

${ }^{27}$ Although the law is simple in that each individual may transfer $\$ 10,000$ per year, tax free, to as many people as they wish, in practice the situation can be complicated, and the "correct amount" difficult to discern. Depending on how quickly she wishes to dispose of assets, a parent (and her spouse) can potentially give $\$ 10,000$ to everyone in her child's family. For example, a married couple, with a married son, who himself has one child, can make tax-free gifts up to $\$ 60,000$ if each parent gives the maximum to each member of the son's family. In both the HRS and AHEAD, transfers to children-in-law and grandchildren are counted as transfers to the respondent's own child.

${ }^{28}$ Some of those with assets valued at less than $\$ 600,000$ may also be attempting to behave strategically. They may be aware of possible future windfall gains and be distributing wealth accordingly in anticipation of the eventual need to avoid taxes, or they may be unaware of the current exempt limit. The level at which an estate is required to file a return (currently $\$ 600,000$ ) has increased dramatically since 1981 . In 1981 the amount was $\$ 175,000$. If individuals
} 
Figure 1 shows the average total transfers by wealth category for the HRS and AHEAD respondents who made at least one transfer. The spike in giving at levels of wealth greater than $\$ 600,000$ is much greater in AHEAD than in the HRS.

\subsection{Transfers from parents}

The empirical predictions of the model are outlined at the beginning of section 3 . I examine first the probability that a parent (or parent couple) makes an inter vivos transfer, and then the probability she makes a bequest. Each family contributes one observation to the estimation.

Inter vivos transfers ought to depend more strongly on the child(ren)'s current income than do bequests, while bequests depend more on permanent income. Current income for the children of the family is measured here as the mean income calculated across siblings. ${ }^{29}$ Permanent income of the children is proxied by mean schooling. Mean age, and an indicator of whether all children in the family own a home are included as a measure of potential liquidity constraints. Home ownership may also proxy permanent income.

To capture differences in behavior due to potential taxes on the estate I include an indicator of whether the parent has assets of over $\$ 600,000$ (or 1.2 million for a couple), the expected survival probability, and the interaction of these two variables. In addition, I control for characteristics of the parent that may be correlated with tastes for transfers and financial ability to make transfers, including age of the parent, race, sex, health status, schooling, income and wealth.

\subsubsection{Inter vivos transfers}

Table 4 presents the results from a logit model for the probability a parent makes a transfer to at least one child. In both the HRS and AHEAD samples the probability falls significantly as the income of the children increases. In the HRS an increase of $\$ 10,000$ in the average income of children is associated with a 4 percentage point decrease in the probability of a transfer on a

\footnotetext{
have previous experience in the settlement of an estate, they may have remembered the earlier figure and be acting upon that number, unaware of the subsequent changes in the law. Alternatively, those with assets above $\$ 600,000$ may not yet have begun to decumulate wealth believing that they have enough time to dispose of assets or that they will be able to consume the wealth themselves before their death.

${ }^{29}$ As noted in the discussion of table $1 \mathrm{~b}$, parents give categorical responses for the income of their children. To average income across children I assign each child a value of income equal the midpoint of the category in which his parent places his income. For the children of AHEAD respondents I also tried imputing a single value within each interval using the distribution of income of HRS respondents who are of similar age to the AHEAD children. The results were substantially unchanged.
} 
base probability of 30 percent. ${ }^{30}$ The effect in AHEAD is just over 1 percentage point on a base of 26 percent. The probability also falls significantly with the mean age as older children are less likely to face liquidity constraints than younger children. The coefficient on schooling is positive and significantly different from zero in both surveys. If schooling is a proxy for permanent income, the probability of a transfer ought to fall with increases in this variable. One explanation for the direction of the effect is that the schooling coefficient may be correlated with an unobserved measure of generosity; parents who gave generously to support a child's education may also be generous with later transfers. I investigate this possibility later in fixed effect models. Alternatively, holding income constant, high levels of schooling signal that current income is less than permanent income.

The largest effect in AHEAD is on the variable indicating whether all children in the family own a home. If all children do own a home it is unlikely that any is facing significant liquidity constraints and the probability of a transfer falls by 5 percentage points. It likely also indicates a reasonably high level of permanent income for each child. The effect in the HRS is similar in magnitude but is not significantly different from zero.

The effects of the parent's characteristics accord with intuition: more educated, wealthier, and higher income parents are more likely to have made a transfer. Moving from the lowest to the highest income quartile increases the probability of a transfer by 20 percentage points in the HRS and 25 in AHEAD. Differences by wealth quartile are only slightly smaller. Nonwhites are significantly less likely than whites to have made an inter vivos transfer as are married respondents. Holding household financial status constant, married individuals have fewer resources per person and are therefore less financially well off than unmarried. Poor health reduces the probability of a transfer, perhaps indicating expected future medical expenses and a need to conserve resources.

As explained in the previous section, inter vivos transfers may be made by wealthy individuals to reduce the tax burden on the eventual estate. In the HRS the individuals with taxable estates are significantly more likely to have made a transfer, and from the coefficient on the interaction term, this probability decreases with an increase in the individual's survival probability. In AHEAD there is not a significant linear effect and the interaction is positive.

\footnotetext{
${ }^{30}$ The effects are evaluated at the means of the right hand side variables. A change of one standard deviation in mean income is equal to $\$ 15,000$ in the HRS and $\$ 20,000$ in AHEAD.
} 


\subsubsection{Bequests}

For the predictions relevant to bequest behavior I use responses to questions in AHEAD that ask respondents to report, on a scale of zero to 100 , (i) the probability with which they expect to leave a bequest, (ii) the probability of leaving more than $\$ 10,000$, and (iii) the probability of leaving more than $\$ 100,000$. I estimate separate ordinary least squares regressions (OLS) for these three probabilities. $^{31}$ These results are presented in table 5 .

In contrast to the results for the probability of making an inter vivos transfer, the probability of leaving a bequest is positively and significantly related to the mean income of the children although the effect is small. An additional $\$ 10,000$ increases the probability by less than 1 percentage point. ${ }^{32}$ This positive relationship between transfers and the recipients' income is a direct contradiction of the predictions of the standard altruism model. The probability of a bequest is also positively and significantly related to the mean schooling level of the children, a proxy for lifetime income.

As with inter vivos transfers, the probability of a bequest significantly increases with both the parent's income and wealth. However, holding wealth quartile constant, having a (potentially) taxable estate does not alter the subjective probability of leaving a bequest.

AHEAD also asks the respondent to report the probability that the amount of the bequest will be greater than $\$ 10,000$ and greater than $\$ 100,000$. The next two sets of estimates in table 5 are OLS regressions for these two probabilities. The coefficient on the mean income of children is positive in both cases and significantly different from zero in the first case, suggesting that the amount of a bequest is positively correlated with the income of the children. These results are inconsistent with the predictions of the standard altruism model.

A potential explanation for the positive correlation between the probability of bequests and the income of children is that the income and wealth quartiles used in this specification are insufficient to capture the effects of parental resources, and that the positive coefficient is the result of the correlation between the resources of parents and children. I note first that this possibility does not explain the differing effects of children's income on inter vivos transfers and bequests. Furthermore,

\footnotetext{
${ }^{31}$ The probability questions were asked of both respondents in the case of married couples. When there are two responses for a family $I$ use the average of the responses. The correlation between the answers of husbands and wives is roughly 0.60 . The conclusions are unchanged if $I$ use the response of the husband or the wife alone.

${ }^{32}$ If bequests are much larger than inter vivos transfers, an increase of 1 percentage point in the probability of receiving a bequest may imply a larger increase in the expected value of transfers than the corresponding decrease in inter vivos gifts associated with an increase in income.
} 
specifications using fourth degree polynomials in the income and wealth of the parent, and specifications with piece-wise linear spline formulations did not yield materially different coefficients on the mean income of children.

\subsubsection{Identical transfers}

In this section I examine the probability of providing for children equally with respect to inter vivos transfers and bequests. In table 6 I present the estimates from a logit model with the dependent variable equal to one if the parent treats all children equally with respect to inter vivos transfers. I then compare these results with a similar equation for the probability of making equal bequests using the AHEAD sample (table 7). ${ }^{33}$ Respondents with fewer than two children are excluded from analyses. In the case of inter vivos transfers, I also exclude those parents who do not make a transfer to at least one child. In the equation analyzing bequest behavior I exclude those parents who do not have a will or who do not name at least one child in their will. ${ }^{34}$ To look at differences across children I add to this pair of regressions the difference between the highest and lowest values of child income, schooling and age.

With respect to inter vivos transfers, the greater the difference in income between the highestand the lowest-income child, the lower the probability of treating children equally. Each $\$ 10,000$ difference in income is associated with a decrease of just under 2 percentage points in the probability of treating children equally (on a mean probability of 6 percent in the HRS and 25 percent in AHEAD). If all children own a home, however, the probability of equal treatment is increased although the effect is not significantly different from zero in the HRS. These results are consistent with differences in expected current consumption driving differences in inter vivos transfers.

The indicator of whether the parent has assets above the taxable limit has strong explanatory power in both data sets is. One would expect wealthy parents, especially those nearing the end of their lives, to be giving strategically to avoid estate taxes and therefore making transfers up to the taxable limit. Although income and wealth alone have no effect on the probability of equal treatment, having a large estate increases the probability by 12 percentage points in the HRS and

\footnotetext{
${ }^{33}$ For married couples the response of the husband is used. Responses of spouses differ in just over 6 percent of the cases.

${ }^{34}$ In a probit analysis (not shown) the probability of having a will is positively related to a parent's income and wealth and negatively related to her probability of survival, although there is no effect of poor health. Whites are more likely to have a will than are nonwhites.
} 
by 35 percentage points in AHEAD. The smaller effect in the HRS relative to AHEAD is consistent with the hypothesis that older parents, nearer to the point of making a bequest, are more likely to behave strategically. Similarly, the effect of having a large potential estate is dampened significantly for those with longer life expectancy.

In AHEAD a parent in poor health is less likely to make equal inter vivos transfers. This effect is not predicted by the model but suggests the possibility of an exchange relationship wherein a child who provides care for a sick parent is reimbursed financially.

Table 7 repeats the analysis for the probability of equal bequests using just the AHEAD sample. Differences in the incomes of children do not affect the probability of equal bequests, but differences in schooling and greater mean age are associated with a significantly lower probability of equal transfers. The greater the differences in schooling levels, the more likely there are to be significant differences in the permanent income of the children. A greater mean age implies perhaps a better estimate of permanent income.

The characteristics of the parent are relatively unimportant in explaining equal bequests, although again parents in poor health are significantly less likely to make equal bequests than healthier parents.

From the differences between the estimated effects of children's income in tables 6 and 7 it is apparent that the factors related to equal inter vivos transfers differ from those associated with equal bequests. Differences in inter vivos transfers are strongly associated with differences in current income while differences in bequests are associated with differences in permanent income. The classic models of altruism and exchange offer no explanation for the differing behavior or for the overwhelming tendency to make equal bequests.

\subsection{Child's point of view}

I now turn to examine transfers from the point of view of the children, estimating both the probability that a child receives an inter vivos transfer and the probability he receives a bequest. I use child-based samples from each survey in which each eligible child of a HRS or AHEAD respondent contributes one observation, and estimate separate equations for the HRS and AHEAD samples. The estimated equations include the child's current income as well as schooling. Also included are age, sex, homeownership, marital status, and indicators of own children, and distance to parent's 
home.

It is likely that there are unobserved differences across families that are correlated with transfer behavior and with some of the right hand side variables. For example, parents who put a great deal of weight on their child's utility may have provided generous inter vivos transfers in the past, thus allowing the child to purchase a home. If these same parents continue to provide generous transfers in the current period, then home ownership is positively correlated with an unobserved measure of generosity included in the error term. Similarly, schooling level may depend on unobserved differences in the parental propensity to make a transfer to the child. The results in the previous section are consistent with these scenarios; home ownership and schooling were consistently positively related to transfers. I therefore take advantage of the multiple observations within families to estimate fixed effect models. Specifications that do not include family fixed effects but control for the observable characteristics of the parents are discussed in Appendix 2 and the estimated regressions are reported in tables $\mathrm{A} 1$ and A2. I use a fixed effect logit specification (Chamberlain, 1980) for the probability of receiving and inter vivos transfer and the probability of being named in a will, and fixed effect OLS regression for the amount of the transfer.

\subsubsection{Receipt of inter vivos transfers}

The estimates for the probability of receiving an inter vivos transfer are presented in table 8 . The results are similar across data sets. Consistent with both the standard altruism model and the variant on it developed here, the probability of receiving an inter vivos transfer varies inversely with a child's income. A child in the lowest income category in the HRS has a 14 percentage point greater probability of receiving a transfer than a child in the highest income category. In AHEAD the difference in the probability between the lowest and the highest income category, is 32 percentage points.

Additional years of schooling have no effect on the probability of a transfer. This result is consistent with the model wherein current income has a large effect on inter vivos transfers, while permanent differences associated with characteristics such as schooling have less of an effect. Home ownership, a second potential proxy for permanent income, or alternatively an indicator of a low probability of liquidity constraints, negatively affects the probability of a transfer.

Older children, who would be less likely to be liquidity constrained, are also less likely to receive 
an inter vivos transfer than are their siblings. There is no difference in the probability of receiving a transfer by the sex of the child. Children who live within 10 miles of their parents or who have children of their own are more likely to receive a transfer than their siblings. All else constant, HRS and AHEAD children with children of their own are more likely to face additional expenses which may put pressure on family finances. Alternatively, because transfers to grandchildren are combined with transfers to children in the surveys, the strong positive coefficient on the variable indicating the existence of grandchildren could simply be capturing the fact that parents give generously to grandchildren. ${ }^{35}$

In the HRS married children are significantly less likely to receive a transfer than single children. This result seems to be inconsistent with the altruism model; holding household income constant, married couples have less income per person, and are therefore less well off than singles. The altruism model would predict that these children would receive greater transfers than single children. However, married children have a second set of parents (in-laws) who can potentially provide assistance; with twice as many parents, any particular parent may be less likely to provide assistance in a given period. Furthermore, with two potential earners to cushion negative shocks to income, married couples are less likely to be liquidity constrained than are singles, and the negative coefficient may be picking up this difference.

The same general results hold when examining the amount of the transfer. Table 9 reports the results for a fixed effects OLS regression for the amount received by children in families that made at least one transfer. For both the HRS and AHEAD samples, a monotonically negative relationship is evident between the child's income and the amount of the transfer. HRS children with family income of less than $\$ 10,000$, on average receive approximately $\$ 1214$, more than children with incomes over $\$ 25,000$. The difference between the highest and lowest income categories in AHEAD is $\$ 1053$. The coefficients on other variables are, for the most part, not significantly different from zero and do not show consistent patterns across data sets.

\footnotetext{
${ }^{35}$ Transfers to grandchildren above a specific amount are subject to a "generation skipping tax" which mitigates the tax incentive to transfer directly to grandchildren.
} 


\subsubsection{Receipt of Bequests}

I now examine whether the patterns for the receipt of a bequest differ from the patterns for the receipt of inter vivos transfers for the sample of children of AHEAD parents. ${ }^{36}$ The sample for table 10 consists of only those children whose parents report having a will, although the will need not name any of the parent's children. Because this is a fixed effects logit analysis, only those families that do not make equal bequests contribute to the likelihood function. Since equal bequests are by far the dominant outcome, the sample size in this analysis is much smaller than in the previous tables.

Even among this select group who do differentiate among children, the probability that a particular child is named in the will is not related to the child's income as would be predicted by the standard altruism model. These results are similar to those of Dunn and Phillips (1997) who find that the child's income affects the probability of an inter vivos transfer but not a bequest. ${ }^{37}$ Schooling, however, is positively and significantly related to the probability of receiving a bequest. This result is at odds with the predictions of the model developed here in which greater permanent income is associated with a lower probability of a bequest.

Older children are somewhat less likely to be named in a will while those who live within ten miles of the parent are significantly more likely to be named. Living within 10 miles of the parent increases the probability of receiving bequests by 13 percentage points. This large difference may indicate that children who live nearby provide care or support to the parent.

\section{Conclusions}

The prevalence of equal bequests has long presented a puzzle to ecohomists. Equal giving is inconsistent with the standard models of altruism or exchange driven behavior that have been used to describe inter vivos giving. Furthermore, because of data limitations past work has focused on the bequest behavior of the wealthiest segment of the population. It is not obvious that the behavior of this group is representative of the population as a whole.

This paper addresses these two issues. It presents a unified model that permits different behavior

\footnotetext{
${ }^{36}$ Information on children named in a will is not available in the HRS. Neither survey contains information on the expected amount or fraction of the eventual estate earmarked for a particular child.

${ }^{37}$ Dunn and Phillips also report the probability of equal treatment with respect to trusts, life insurance policies, and deeds to a parent's home.
} 
for inter vivos transfers and bequests. Parents are assumed to base transfers on the expected consumption level of the child; current transfers depend on expected current consumption, and future transfers (bequests) on expected future consumption. Current income is a better predictor of current consumption than of future consumption and is therefore more strongly correlated with inter vivos transfers than with bequests. Under some circumstances the model predicts a nonnegative relationship between the child's income and bequests- an empirical fact not explained by other models.

This paper also adds to the current literature by examining bequest behavior for a nationally representative sample of individuals, and by analyzing inter vivos giving and bequests using the same sample of individuals. The patterns of bequest behavior for this representative sample are generally similar to the behavior of the wealthiest segment of the population as observed in probate records.

The theoretical model is well supported by the empirical work. Inter vivos transfers are given disproportionately to financially less well-off children, while the allocation of bequests is un related to a child's current income. Furthermore, unequal bequests are more likely to be made when children have different expected levels of permanent income.

In addition to the compensatory inter vivos transfers predicted by the model, parents who are likely to leave large (taxable) estates are observed to make tax-driven inter vivos transfers. These transfers, perhaps more properly thought of as early bequests, are made to reduce the inheritance taxes eventually faced by the estate. In response to the details of the tax code, these transfers are made in roughly $\$ 10,000$ increments and are likely to be made equally across children. 


\section{References}

[1] Altonji, Joseph G., and Thomas Dunn (1992), "Relationships Among the Family Incomes and Labor Market Outcomes of Relatives." Research in Labor Economics, 12: 269-310.

[2] Altonji, Joseph G., Fumio Hayashi and Laurence Kotlikoff (1992), "Is the Extended Family Altruistically Linked? Direct Evidence Using Micro Data," American Economic Review 82(5):1177-1198.

[3] Altonji, Joseph G., Fumio Hayashi and Laurence Kotlikoff (1994). "Parental Altruism and Inter Vivos Transfers: Theory and Evidence." mimeo, Northwestern University, February.

[4] Andreoni, James (1989). "Giving with Impure Altruism: Applications to Charity and Ricardian Equivalence." Journal of Public Economics, 97(6): 1447-1458.

[5] Barro, Robert J. (1974). "Are Government Bonds Net Wealth?" Journal of Political Economy, 82(6): 1095-1117.

[6] Becker, Gary (1974). "A Theory of Social Interactions." Journal of Political Economy, 82(6): 1063-1093.

[7] Behrman, Jere, Robert Pollak and Paul Taubman (1990). "Parental Preferences and Provision for Progeny." Journal of Political Economy, 90(1): 52-73.

[8] Bernheim, B. Douglas, Andrei Shleifer, and Lawrence H. Summers (1985). "The Strategic Bequest Motive.” Journal of Political Economy, 93(6): 1045-1076.

[9] Browning, Martin and Annamaria Lusardi (1996). "Household Savings: Micro Theories and Micro Facts." Journal of Economic Literature, 34(4): 1797-1855.

[10] Chamberlain, Gary (1980). "Analysis of Covariance with Qualitative Data." Review of Economic Studies, 47: 225-238.

[11] Cox, Donald (1987)."Motives for Private Income Transfers." Journal of Political Economy, 95(3): 509-546. 
[12] Cox, Donald and Mark Rank (1992). "Inter-vivos Transfers and Intergenerational Exchange." Review of Economics and Statistics, 74(2): 305-314.

[13] Deaton, Angus (1992). Understanding Consumption, Oxford: Claredon Press.

[14] Dunn, Thomas (1994). "The Distribution of Intergenerational Income Transfers Across and Within Families." mimeo, Syracuse University.

[15] Dunn, Thomas and John Phillips (1997). "Do Parents Divide Resources Equally Among Children? Evidence from the AHEAD Survey." Aging Studies Program Paper No. 5, Syracuse University.

[16] Gale, William and John Karl Scholz (1994). "Intergenerational Transfers and the Accumulation of Wealth." The Journal of Economic Perspectives, 8(4): 145-160.

[17] Hall, Robert and Frederic Mishkin (1982). "The Sensitivity of Consumption to Transitory Income: Estimates from Panel Data on Households." Econometrica, 50(2): 461-481.

[18] Hurd, Michael (1987). "Savings of the Elderly and Desired Bequests." American Economic Review, 77(3): 298-312.

[19] Internal Revenue Service (1992). "Federal Estate and Gift Taxes." Department of the Treasury, publication 448 .

[20] Juster, F. Thomas and Richard Suzman (1995), "The Health and Retirement Study: an Overview." Journal of Human Resources, 30: s7-s56.

[21] Kurz, Mordecai (1984), "Capital Accumulation and the Characteristics of Private Intergenerational Transfers.” Economica, 51:1-22.

[22] Lillard, Lee A. and M. Rebecca Kilburn (1996). "Assortative Mating and Family Links in Permanent Earnings,' mimeo, RAND.

[23] McGarry, Kathleen and Robert F. Schoeni (1995). "Transfer Behavior: Measurement, and the Redistribution of Resources Within the Family." Journal of Human Resources, 30: s184-s226.

[24] McGarry, Kathleen and Robert F. Schoeni (1997). "Transfer Behavior within the Family: Results from the Asset and Health Dynamics Survey." Journals of Gerontology, 52B: 82-92. 
[25] Menchik, Paul L. (1980). "Primogeniture, Equal Sharing, and the U.S. Distribution of Wealth?" The Quarterly Journal of Economics, 94(2): 299-316.

[26] Menchik, Paul L. (1988). "Unequal Estate Division: Is it Altruism, Reverse Bequests, or Simply Noise?" in Modelling the Accumulation and Distribution of Wealth, eds. Denis Kessler and Andre Mason. New York: Oxford University Press.

[27] Soldo, Beth, Michael Hurd, Michael, Willard Rodgers, and Robert Wallace (1997). "Asset and Health Dynamics among the Oldest Old: an Overview of the Survey." Journals of Gerontology, 52B: $1-20$.

[28] Solon, Gary, Mary Corcoran, Roger Gordon, Deborah Laren (1991). “A Longitudinal Analysis of Sibling Correlations in Economic Status," Journal of Human Resources, 26(3): 509-534.

[29] Tomes, Nigel (1988). "Inheritance and Inequality Within the Family: Equal Division Among Unequals, or do the Poor Get More?" In Modelling the Accumulation and Distribution of Wealth, eds. Denis Kessler and Andre Mason. New York: Oxford University Press.

[30] Wilhelm, M.O. (1996). "Bequest Behavior and the Effect of Heirs' Earnings: Testing the Altruistic Model of Bequests." forthcoming in American Economic Review.

[31] Yaari, Menachim E. (1965). "Uncertain Lifetime, Life Insurance, and the Theory of the Consumer." Review of Economic Studies, 32(2): 137-150.

\section{Appendix 1}

The model outlined in section 2 yields the following comparative statics. Let

$$
\begin{aligned}
a_{1} & =\alpha\left(\frac{\tau^{2}}{\tau^{2}+\sigma^{2}}\right)+\gamma\left(\frac{\sigma^{2}}{\tau^{2}+\sigma^{2}}\right) . \\
a_{2} & =\gamma\left(\frac{\sigma^{2}}{\tau^{2}+\sigma^{2}}\right) . \\
q_{22} & =\left(V^{\prime}\right)^{2} U_{22}+U_{2} V^{\prime \prime} . \\
d e t & =\alpha^{2} U_{11} q_{22}-\left(\alpha V^{\prime}\right)^{2} U_{12} U_{21}+\alpha^{2} B^{\prime \prime} U_{11}-2 \alpha^{3} B^{\prime \prime} U_{12} V^{\prime}+\alpha^{4} B^{\prime \prime} q_{22} . \\
\frac{\partial t}{\partial w_{p}}= & \frac{\alpha^{2} U_{11} B^{\prime \prime}-\alpha^{3} V^{\prime} U_{12} B^{\prime \prime}}{\operatorname{det}} .
\end{aligned}
$$




$$
\begin{aligned}
\frac{\partial b}{\partial w_{p}} & =\frac{\left(\alpha V^{\prime}\right)^{2}\left(U_{11} U_{22}-U_{12} U_{21}\right)+\alpha^{2} U_{11} V^{\prime \prime} U_{2}}{\operatorname{det}} . \\
\frac{\partial t}{\partial y_{k}} & =\frac{-\alpha a_{1} U_{11} q_{22}+\alpha a_{2} U_{11} B^{\prime \prime}+\alpha^{2} B^{\prime \prime} U_{12} V^{\prime}\left(a_{1}-a_{2}\right)-\alpha^{3} B^{\prime \prime} a_{1} q_{22}+\alpha a_{1}\left(V^{\prime} U_{12}\right)^{2}}{\operatorname{det}} . \\
\frac{\partial b}{\partial y_{k}} & =\frac{\alpha a_{1} U_{11} q_{22}-\alpha a_{2} U_{11} B^{\prime \prime}+\alpha^{2} 2 a_{2} B^{\prime \prime} U_{12} V^{\prime}-\alpha^{3} B^{\prime \prime} a_{2} q_{22}-\alpha a_{1}\left(V^{\prime} U_{12}\right)^{2}}{\operatorname{det}} .
\end{aligned}
$$

\section{Appendix 2: Estimates without fixed effects}

The probability that a child receives an inter vivos transfer or is named in a will, and the amount of an inter vivos transfer were analyzed in tables 9,10 , and 11 controlling for unobserved differences across families through fixed effects analyses. This appendix presents estimates from regressions excluding these fixed effects. There are several differences between the two specifications which provide insight into transfer behavior.

\section{A.1 Probability of receipt}

Table A1 gives the results for a model of the probability of receipt of an inter vivos transfer or bequest. For both samples the coefficients on a child's income show the same basic pattern as in the fixed effects versions; the probability of an inter vivos transfer is inversely related to the child's income. There is also information in a "don't know" response. If, for example, a parent cannot say whether a child's income is less than $\$ 20,000$, but she does know that the child's income is less than $\$ 30,000$, she is permitted to report this broader range. If a parent cannot report a child's income with precision, it is likely that she is inattentive to the child's financial status and is therefore less likely to make a transfer. This relationship is observed in the data but "differences out" when family fixed effects are controlled for. Taking the less than $\$ 30,000$ category in AHEAD as an example, one would expect the coefficient for this income category to be a weighted average of the coefficients for income less than $\$ 20,000$ and for income between $\$ 20,000$ and $\$ 30,000$. However, the estimated coefficient is lower, indicating that the inability to report a child's income accurately is associated with a lower probability that the child receives a transfer. At the extreme, in each data set a large negative coefficient is associated with the income missing category. Note also that the coefficient on schooling is positive and significant in both samples in this logit specification, but not so in the fixed effects models. This result is consistent with the hypothesis that parents who provided 
financial support to allow a child to obtain additional schooling continue to provide resources to this child. When unobserved parental generosity is controlled for, the correlation between transfer probability and schooling disappears.

Turning to parental characteristics that are lost in a fixed effects model, children of wealthier, higher income, more schooled parents are more likely to receive a transfer, while being nonwhite and having more siblings decreases the probability. Insight into the importance of tax incentives in driving the behavior of older wealthier individuals is apparent in the coefficient on the dummy variable indicating assets over $\$ 600,000$ (taxable estate). Having parents with assets over $\$ 600,000$ (after controlling for wealth quartile) has a large positive effect on the probability of a child receiving a transfer in the HRS, and the effect is reduced the longer a parent expects to live (prob head lives*taxable estate). Surprisingly, the results are less strong in AHEAD although there is a significant negative relationship between the probability of a transfer and the probability of survival.

In the final pair of columns, the probability of being named in a will is again not related to the child's income, except for the children in the income missing category.

\section{A.2 Amount of inter vivos transfer}

The results from the HRS analysis of the amount of the transfer again point to compensatory giving, with more going to less well- off children. The results for AHEAD however, are less clear cut. The difference is likely due, at least in part, to transfers made to avoid eventual estate taxes. As shown in table $\mathrm{A} 3$, if children receiving transfers of $\$ 10,000$ or more are excluded from the sample, there is a strong and consistently monotonic relationship between income and the size of the transfer in both data sets. Ignoring the unobserved differences across families, older children are less likely to receive a transfers, while children who own a home or who have more schooling receive greater transfers.

The same patterns are evident for the relationship between parental income and wealth as existed in the equations for the probability of a transfer. Transfers increase by a large amount if the parent has assets in excess of $\$ 600,000$ and in both data sets the effect decreases with increases in the life expectancy of parents. 


\section{HRS}

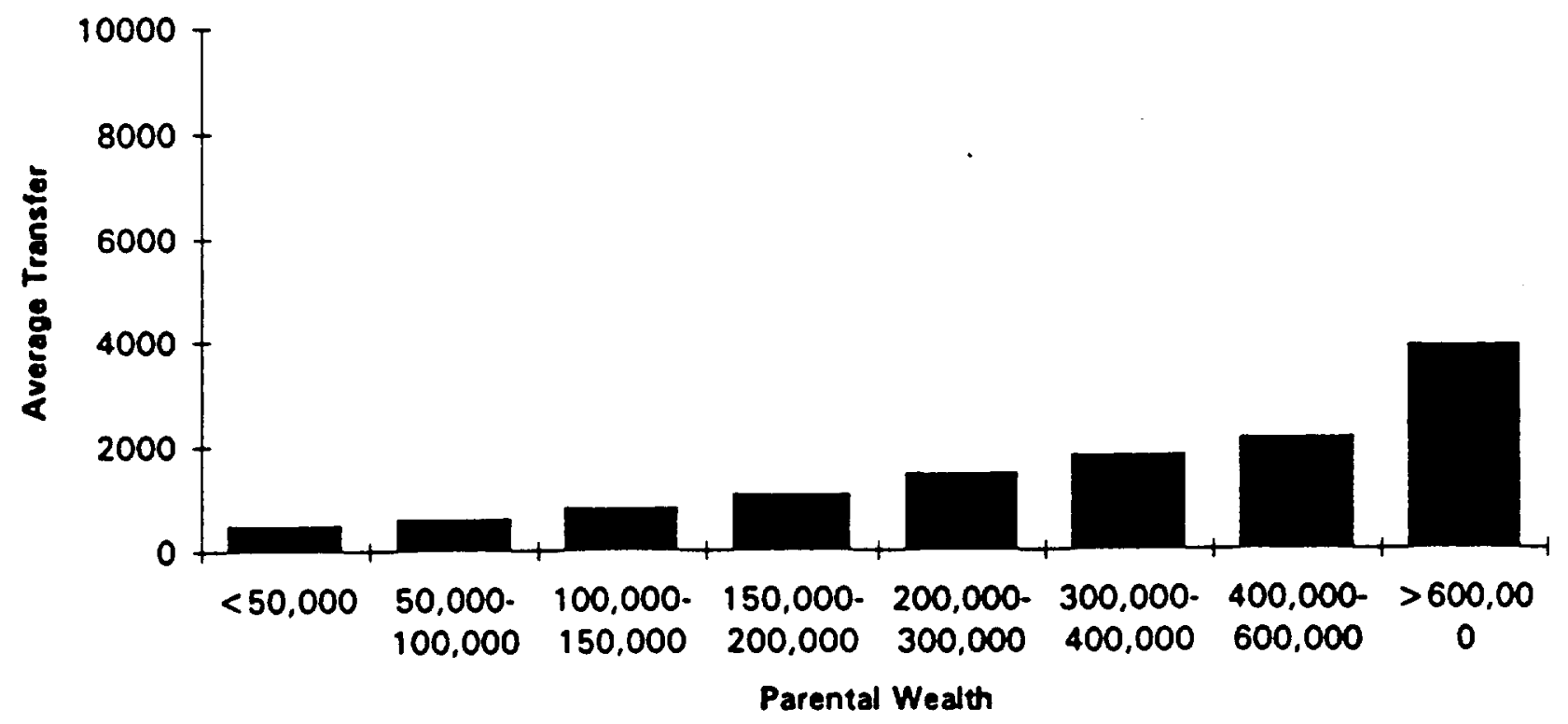

\section{AHEAD}

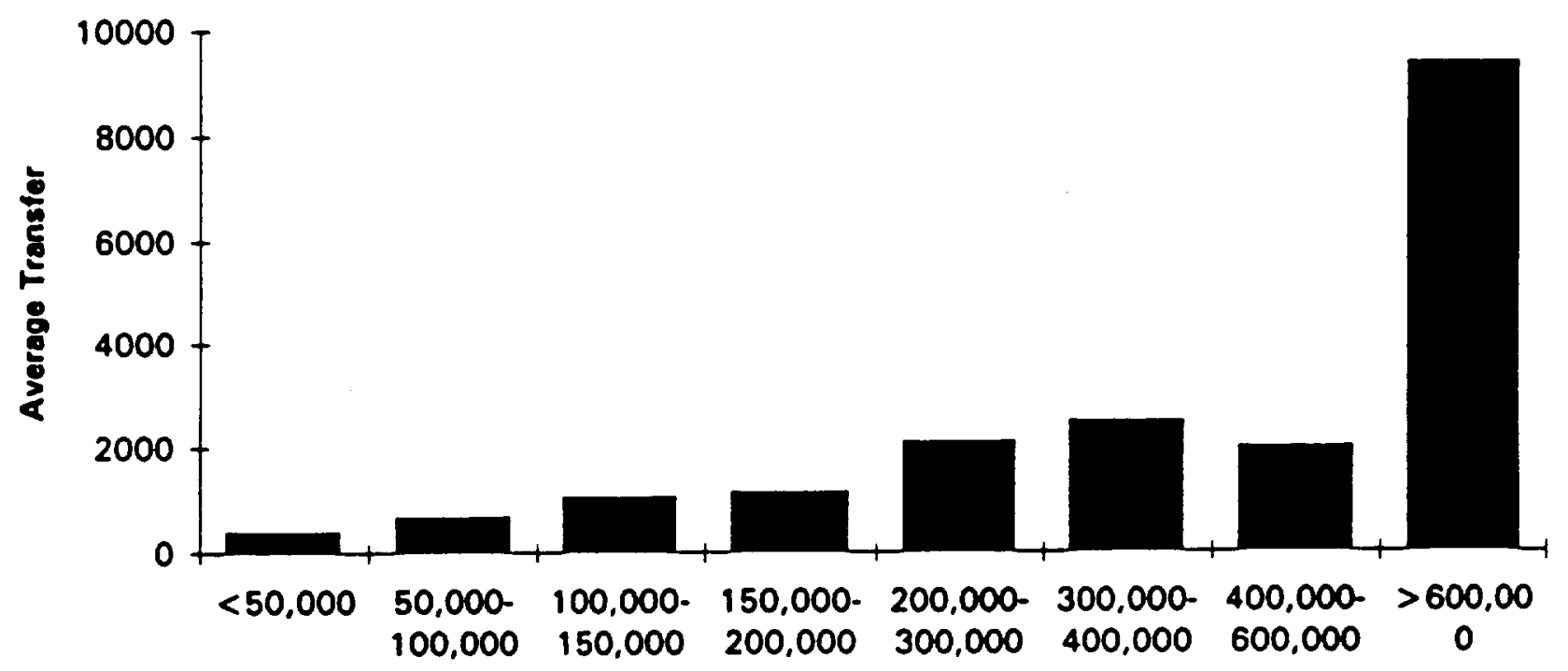

Parental Wealth 
Table 1a

Means of Variables used in the Analyses

HRS and AHEAD Respondents

\begin{tabular}{l|rrrr}
\hline & \multicolumn{2}{|c}{ HRS } & \multicolumn{2}{c}{ AHEAD } \\
& \multicolumn{2}{|c}{$\left(\mathrm{n}=6181^{*}\right)$} & $\left.4835^{*}\right)$ \\
\hline & Mean & Std Err & Mean & Std Err \\
\hline Age of head & 57.43 & 0.06 & 77.71 & 0.08 \\
Income (head and spouse) & 41,214 & 616 & 21,790 & 349 \\
Wealth (head and spouse) & 248,377 & 5178 & 167,010 & 4727 \\
Wealth > $\$ 600,000$ & 0.039 & 0.002 & 0.021 & 0.002 \\
Nonwhite (head) & 0.148 & 0.004 & 0.155 & 0.005 \\
Highest grade completed of head & 12.14 & 0.035 & 11.24 & 0.085 \\
Male in household & 0.794 & 0.004 & 0.532 & 0.007 \\
Married & 0.696 & 0.005 & 0.415 & 0.006 \\
Number of living children & 3.02 & 0.020 & 2.92 & 0.025 \\
Head or spouse in poor health & 0.304 & 0.005 & 0.427 & 0.006 \\
Probability of head living to 75 & 0.65 & 0.003 & - & - \\
Probability of head living approx 10 years & - & - & 0.35 & 0.005 \\
\hline " Number of observations differs for some variables due to missing values. \\
\hline
\end{tabular}


Table 1b

Means of Variables used in the Analyses

HRS and AHEAD Children

\begin{tabular}{l|rrrr}
\hline & \multicolumn{2}{|c}{$\begin{array}{c}\text { HRS } \\
\left(\mathrm{n}=18,874^{*}\right)\end{array}$} & \multicolumn{2}{c}{ AHEAD } \\
& $\left.\mathrm{n}=14,249^{*}\right)$ \\
\hline & Mean & Std Err & Mean & Std Err \\
\hline Age & 30.83 & 0.03 & 47.19 & 0.07 \\
Total Family Income HRS & & & & \\
less than $\$ 10,000$ & 0.151 & 0.002 & - & - \\
$\$ 10,000-25,000$ & 0.293 & 0.003 & - & - \\
greater than 25,000 & 0.402 & 0.003 & - & - \\
Total Family lncome AHEAD & & & & \\
less than $\$ 20,000$ & - & - & 0.118 & 0.002 \\
$\$ 20,000-30,000$ & - & - & 0.115 & 0.002 \\
$\$ 30,000-50,000$ & - & - & 0.220 & 0.003 \\
greater than 50,000 & - & - & 0.227 & 0.003 \\
less than $\$ 30,000$ & - & - & 0.022 & 0.001 \\
less than $\$ 50,000$ & - & - & 0.040 & 0.001 \\
greater than $\$ 30,000$ & - & - & 0.055 & 0.002 \\
Total Family Income missing & 0.154 & 0.002 & 0.203 & 0.003 \\
Male & 0.501 & 0.003 & 0.493 & 0.004 \\
Owns home & 0.462 & 0.003 & 0.750 & 0.003 \\
Lives within 10 miles & 0.397 & 0.003 & 0.343 & 0.004 \\
Married & 0.624 & 0.003 & 0.727 & 0.003 \\
Has children (1=yes) & 0.634 & 0.003 & 0.834 & 0.003 \\
Highest grade completed & 13.02 & 0.014 & 13.30 & 0.021 \\
\hline " Number of observations differs for some variables due to missing \\
values.
\end{tabular}


Table 2

Cash Transfers to Children 18 and over in the HRS and AHEAD Surveys

\begin{tabular}{lcr} 
& HRS & AHEAD \\
\hline $\begin{array}{l}\text { Percent of families } \\
\text { making a cash transfer } \\
\text { to at least one child }\end{array}$ & 28.9 & 24.6 \\
$\begin{array}{l}\text { Percent of children } \\
\text { receiving a cash } \\
\text { transfer }\end{array}$ & & \\
$\begin{array}{l}\text { Mean amount of non-zero } \\
\text { cash transfers }\end{array}$ & 13.4 & 13.1 \\
$\begin{array}{l}\text { Standard Deviation } \\
\quad\end{array}$ & 53013 & $\$ 4215$ \\
Median amount & 1000 & 1500 \\
\hline
\end{tabular}


Table 3

Probability of Leaving a Bequest

Probability leave a bequest

mean

0.554

standard deviation

0.381

median

0.500

Probability leave inheritance $>\$ \$ 10,000$

mean

0.573

median

0.750

standard deviation

0.410

Probability leave inheritance $>\$ 100,000$ mean

0.279

median

0.000

standard deviation 
Table 4

Logit Estimates of the Probability of Making an Inter Vivos Transfer

\begin{tabular}{|c|c|c|c|c|c|c|}
\hline & \multicolumn{3}{|c|}{ HRS } & \multicolumn{3}{|c|}{ AHEAD } \\
\hline & Coeff & Std Err & Deriv ${ }^{\ddagger}$ & Coeff & Std Err & Deriv \\
\hline \multicolumn{7}{|l|}{ Children's Characteristics: } \\
\hline Mean Income $(10,000 \mathrm{~s})^{\dagger}$ & -0.202 & 0.024 & -0.038 & -0.078 & 0.024 & -0.012 \\
\hline Mean age & -0.040 & 0.009 & -0.007 & -0.015 & 0.007 & -0.002 \\
\hline Mean schooling & 0.044 & 0.022 & 0.008 & 0.075 & 0.024 & 0.012 \\
\hline All children own home $(0 / 1)$ & -0.162 & 0.111 & -0.030 & -0.297 & 0.084 & -0.048 \\
\hline \multicolumn{7}{|l|}{ Respondent's characteristics } \\
\hline Age of head (male in couple) & 0.016 & 0.008 & 0.003 & 0.015 & 0.009 & 0.002 \\
\hline $\begin{array}{l}\text { Highest grade completed of head } \\
\text { Income quartile }\end{array}$ & 0.068 & 0.013 & Income quartile & 0.014 & 0.006 & 0.002 \\
\hline 1st-lowest & -1.102 & 0.117 & -0.205 & -1.522 & 0.168 & -0.246 \\
\hline 2nd & -0.659 & 0.097 & -0.122 & -0.917 & 0.124 & -0.148 \\
\hline $3 \mathrm{rd}$ & -0.382 & 0.084 & -0.071 & -0.493 & 0.104 & -0.080 \\
\hline 4th (omitted) & - & - & - & - & - & - \\
\hline \multicolumn{7}{|l|}{ Wealth quartile } \\
\hline 1st-lowest & -0.904 & 0.122 & -0.168 & -0.868 & 0.151 & -0.140 \\
\hline 2nd & -0.351 & 0.097 & -0.065 & -0.680 & 0.124 & -0.110 \\
\hline 3rd & -0.110 & 0.087 & -0.020 & -0.307 & 0.103 & -0.050 \\
\hline 4th (omitted) & - & - & - & - & - & - \\
\hline Taxable estate & 1.157 & 0.442 & 0.215 & 0.215 & 0.374 & 0.035 \\
\hline Prob of head living 10 years $(0-1)$ & - & - & - & -0.109 & 0.135 & -0.018 \\
\hline Prob of head living to $75(0-1)$ & 0.208 & 0.126 & 0.039 & - & - & - \\
\hline Prob of living * taxable estate & -1.410 & 0.840 & -0.262 & 2.154 & 0.804 & 0.348 \\
\hline Nonwhite & -0.254 & 0.092 & -0.047 & -0.301 & 0.131 & -0.049 \\
\hline Married & -0.237 & 0.082 & -0.044 & -0.041 & 0.092 & -0.007 \\
\hline Number of living children & 0.064 & 0.019 & 0.012 & -0.049 & 0.023 & -0.008 \\
\hline Head or spouse in poor health & -0.128 & 0.079 & -0.024 & -0.249 & 0.086 & -0.040 \\
\hline Constant & -0.721 & 0.477 & -0.134 & -0.850 & 0.668 & -0.137 \\
\hline Number of Observations & & 5443 & & & 4098 & \\
\hline Mean of Dependent Variable & & 0.30 & & & 0.26 & \\
\hline \multicolumn{7}{|c|}{$\begin{array}{l}\text { Mean income is obtained by assigning each child the midpoint of his income category and } \\
\text { averaging across all children in the family. Other mean values calculated similarly. }\end{array}$} \\
\hline
\end{tabular}


Table 5

OLS Estimates of the Probability of Bequests

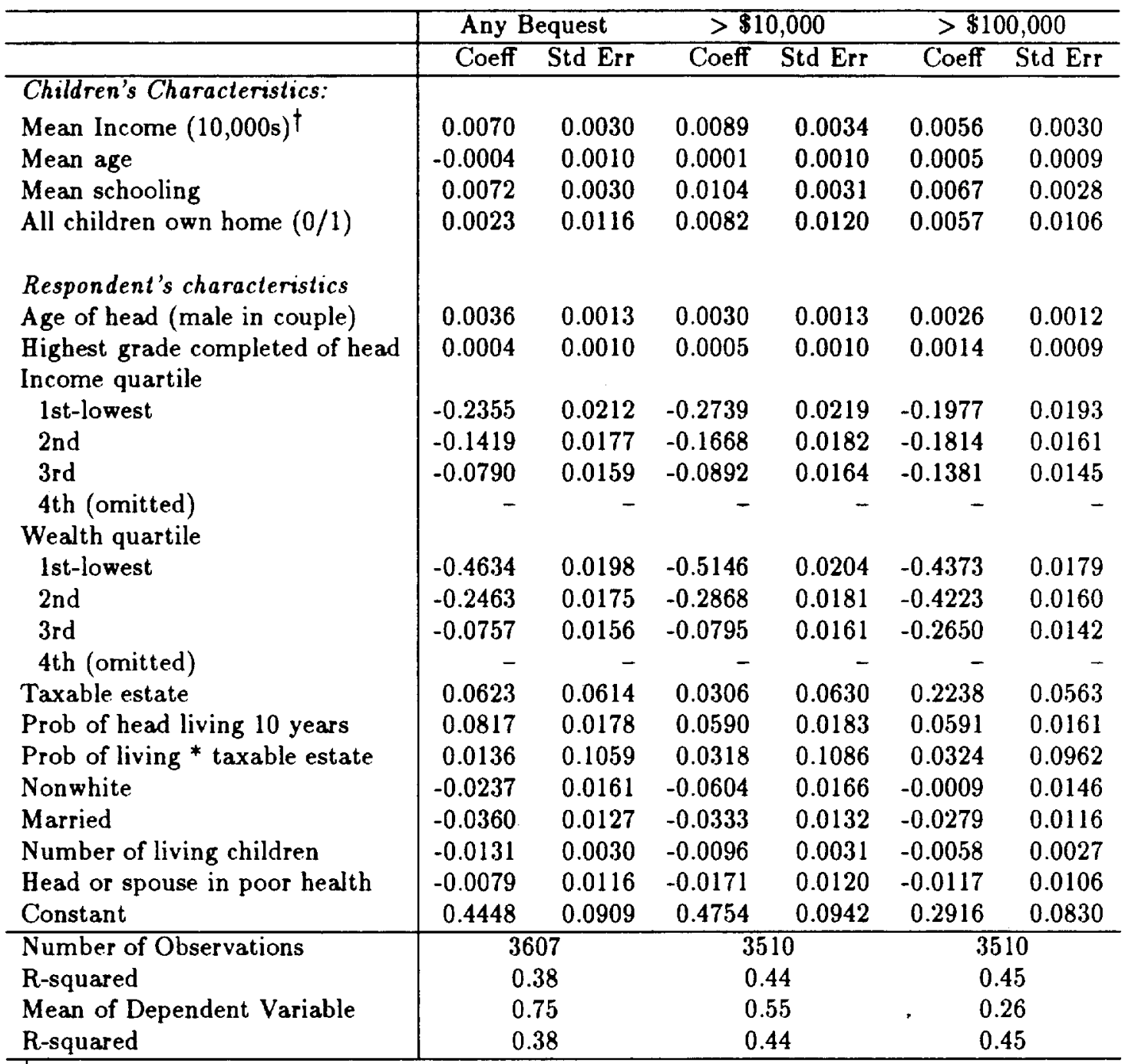

$\dagger_{\text {Mean }}$ income is obtained by assigning each child the midpoint of his income category and averaging across all children in the family. Other mean values calculated similarly. 
Table 6

Logit Estimates of the Probability of Equal Inter vivos Transfers

\begin{tabular}{|c|c|c|c|c|c|c|}
\hline & \multicolumn{3}{|c|}{ HRS } & \multicolumn{3}{|c|}{ ABEAD } \\
\hline & Coeff & Std Err & Deriv* & Coeff & Std Err & Deriv \\
\hline \multicolumn{7}{|l|}{ Children's Characteristics: } \\
\hline Mean Income $(10,000 s)^{\dagger}$ & -0.055 & 0.088 & -0.004 & -0.063 & 0.062 & -0.009 \\
\hline Mean age & -0.039 & 0.035 & -0.003 & -0.010 & 0.021 & -0.001 \\
\hline Mean schooling & 0.245 & 0.085 & 0.019 & 0.119 & 0.068 & 0.018 \\
\hline Difference ${ }^{\ddagger}$ Income $(10,000 \mathrm{~s})$ & -0.249 & 0.074 & -0.019 & -0.100 & 0.048 & -0.015 \\
\hline Difference age & -0.048 & 0.045 & -0.003 & -0.025 & 0.022 & -0.004 \\
\hline Difference schooling & 0.009 & 0.081 & 0.001 & 0.003 & 0.054 & 0.000 \\
\hline All children own home $(0 / 1)$ & 0.123 & 0.360 & 0.009 & 0.874 & 0.219 & 0.132 \\
\hline \multicolumn{7}{|l|}{ Respondent's characteristics } \\
\hline Age of head (male in couple) & 0.009 & 0.031 & 0.001 & 0.031 & 0.025 & 0.005 \\
\hline Highest grade completed of head & -0.068 & 0.049 & -0.005 & 0.032 & 0.022 & 0.005 \\
\hline \multicolumn{7}{|l|}{ Income quartile } \\
\hline 1st-lowest & 0.369 & 0.399 & 0.029 & 0.080 & 0.452 & 0.012 \\
\hline 2nd & -0.071 & 0.409 & 0.005 & -0.959 & 0.357 & -0.145 \\
\hline 3rd & -0.066 & 0.316 & 0.005 & -0.525 & 0.260 & -0.079 \\
\hline 4th (omitted) & - & - & - & - & - & - \\
\hline \multicolumn{7}{|l|}{ Wealth quartile } \\
\hline 1st-lowest & -0.971 & 0.352 & -0.075 & -0.191 & 0.413 & -0.029 \\
\hline 2nd & -0.406 & 0.371 & -0.031 & -0.499 & 0.352 & -0.075 \\
\hline $3 r d$ & -0.854 & 0.338 & -0.066 & -0.620 & 0.252 & -0.093 \\
\hline 4th (omitted) & - & - & - & - & - & - \\
\hline Taxable estate & 1.567 & 0.862 & 0.121 & 2.313 & 1.006 & 0.349 \\
\hline Prob of head living 10 years & 0.384 & 0.533 & 0.030 & -0.423 & 0.357 & -0.064 \\
\hline Prob of living * taxable estate & -1.519 & 1.287 & -0.117 & -3.645 & 1.608 & -0.549 \\
\hline Nonwhite & 0.275 & 0.371 & 0.021 & -0.586 & 0.422 & -0.088 \\
\hline Married & -0.496 & 0.300 & -0.038 & -0.200 & 0.231 & -0.030 \\
\hline Number of living children & -0.689 & 0.198 & -0.053 & -0.172 & 0.104 & -0.026 \\
\hline Head or spouse in poor health & -0.127 & 0.336 & -0.010 & 0.536 & -0.215 & 0.081 \\
\hline Constant & -1.521 & 1.930 & -0.117 & -3.738 & 1.829 & -0.563 \\
\hline Number of Observations & & 1343 & & & 726 & \\
\hline Mean of Dependent Variable & & 0.064 & & & 0.247 & \\
\hline
\end{tabular}

Thean income is obtained by assigning each child the midpoint of his income category and averaging across all children in the family. Other mean values calculated similarly.

†t Differences are defined as the difference between the highest value within the family.

- Derivatives are evaluated at the means of the right hand side variables. 
Table 7

Logit Estimates of the Probability of Equal Bequests

\begin{tabular}{|c|c|c|c|}
\hline & Coeff & Std Err & Deriv* \\
\hline \multicolumn{4}{|l|}{ Children's Characteristics: } \\
\hline Mean Income $(10,000 s)^{\dagger}$ & 0.007 & 0.038 & 0.001 \\
\hline Mean age & -0.050 & 0.013 & -0.007 \\
\hline Mean schooling & 0.104 & 0.037 & 0.016 \\
\hline Difference ${ }^{\dagger \dagger}$ Income $(10,000 \mathrm{~s})$ & 0.008 & 0.030 & 0.001 \\
\hline Difference age & -0.020 & 0.012 & -0.003 \\
\hline Difference schooling & -0.061 & 0.027 & -0.009 \\
\hline All children own home $(0 / 1)$ & 0.475 & 0.130 & 0.071 \\
\hline \multicolumn{4}{|l|}{ Respondent's characteristics } \\
\hline Age of head (male in couple) & 0.012 & 0.016 & 0.002 \\
\hline Highest grade completed of head & -0.009 & 0.009 & -0.001 \\
\hline \multicolumn{4}{|l|}{ Income quartile } \\
\hline 1st-lowest & 0.003 & 0.233 & 0.000 \\
\hline 2nd & 0.155 & 0.191 & 0.023 \\
\hline 3 rd & 0.061 & 0.170 & 0.009 \\
\hline 4th (omitted) & - & - & - \\
\hline \multicolumn{4}{|l|}{ Wealth quartile } \\
\hline 1st-lowest & -0.356 & 0.224 & -0.053 \\
\hline 2nd & -0.114 & 0.186 & -0.017 \\
\hline 3 rd & 0.035 & 0.166 & 0.005 \\
\hline 4th (omitted) & - & - & - \\
\hline Taxable estate & -0.930 & 0.545 & -0.139 \\
\hline Prob of head living 10 years $(0-10)$ & -0.103 & 0.207 & -0.015 \\
\hline Prob of living * taxable estate & 1.401 & 1.029 & 0.209 \\
\hline Nonwhite & -0.431 & 0.206 & -0.064 \\
\hline Married & 0.163 & 0.141 & 0.024 \\
\hline Number of living children & -0.095 & 0.047 & -0.014 \\
\hline Head or spouse in poor health & -0.269 & 0.128 & -0.040 \\
\hline Constant & 2.047 & 1.040 & 0.306 \\
\hline Number of Observations & & 2120 & \\
\hline Mean of Dependent Variable & & 0.819 & \\
\hline
\end{tabular}

TMean income is obtained by assigning each child the midpoint of his income category and averaging across children. Other means calculated similarly.

${ }^{\dagger}$ Differences are defined as the difference between highest value in the family and the lowest value.

* Derivatives are evaluated at the means of the right hand side variables. 
Table 8

Logit Estimates of the Probability a Child Receives an Inter Vivos transfer

Fixed Effects

\begin{tabular}{l|rrrrrr}
\hline & \multicolumn{3}{|c}{ HRS } & \multicolumn{3}{c}{ AHEAD } \\
\hline & Coeff & Std Err & Deriv & Coeff & Std Err & Deriv \\
\hline Child's Characteristics: & & & & & & \\
Total Family Income HRS & & & & & & \\
$\quad$ Less than $\$ 10,000$ & 1.446 & 0.147 & 0.141 & - & - & - \\
10,000-24,999 & 0.931 & 0.110 & 0.091 & - & - & - \\
25,000 or more (omitted) & - & - & - & - & - & - \\
Total Family Income AHEAD & & & & & & \\
Less than $\$ 20,000$ & - & - & - & 1.462 & 0.243 & 0.320 \\
20,000-30,000 & - & - & - & 1.469 & 0.207 & 0.322 \\
30,000-50,000 & - & - & - & 0.351 & 0.171 & 0.077 \\
greater than 50,000 (omitted) & - & - & - & - & - & - \\
less than 30,000 & - & - & - & 1.310 & 0.434 & 0.287 \\
less than 50,000 & - & - & - & 1.301 & 0.375 & 0.285 \\
greater than 30,000 & - & - & - & 0.433 & 0.290 & 0.095 \\
Total Income missing & 0.572 & 0.267 & 0.056 & 0.593 & 0.290 & 0.130 \\
Age & -0.104 & 0.011 & -0.010 & -0.039 & 0.009 & -0.009 \\
Male & -0.035 & 0.078 & -0.003 & -0.166 & 0.105 & -0.036 \\
Own their own home & -0.307 & 0.101 & -0.030 & -0.265 & 0.146 & -0.058 \\
Live within 10 miles & 0.413 & 0.093 & 0.041 & 0.389 & 0.131 & 0.085 \\
Currently married & -0.212 & 0.098 & -0.021 & 0.000 & 0.144 & 0.000 \\
Has at least one child & 0.469 & 0.101 & 0.046 & 0.832 & 0.164 & 0.182 \\
Completed schooling & 0.007 & 0.027 & 0.001 & 0.030 & 0.031 & 0.006 \\
\hline Number of Observations & \multicolumn{7}{|c|}{4015} & & & 2074 & \\
\hline
\end{tabular}

Derivatives are evaluated at the means of the right hand side variables. 
Table 9

OLS Estimates of the Amount of an Inter Vivos Transfer

Fixed Effects

\begin{tabular}{l|rrrr}
\hline & \multicolumn{3}{|c}{ HRS } & \multicolumn{2}{c}{ AHEAD } \\
\hline & Coeff & Std Err & Coeff & Std Err \\
\hline Child's Characteristics: & & & & \\
Total Family Income HRS & & & & \\
Less than $\$ 10,000$ & 1214.06 & 229.65 & - & - \\
$10,000-24,999$ & 573.35 & 194.85 & - & - \\
25,000 or more (omitted) & - & - & - & - \\
Total Family Income AHEAD & & & & \\
Less than $\$ 20,000$ & - & - & 1053.44 & 354.41 \\
$20,000-30,000$ & - & - & 974.24 & 369.41 \\
$30,000-50,000$ & - & - & 456.59 & 291.77 \\
greater than 50,000 (omitted) & - & - & - & - \\
less than 30,000 & - & - & 1120.07 & 506.64 \\
less than 50,000 & - & - & 1327.91 & 835.91 \\
greater than 30,000 & - & - & 689.68 & 446.93 \\
Total Income missing & 74.46 & 420.13 & -195.48 & 624.96 \\
Age & -66.32 & 15.71 & -21.62 & 18.66 \\
Male & 53.74 & 112.31 & -81.71 & 169.58 \\
Own their own home & -36.61 & 147.79 & 68.85 & 208.14 \\
Live within 10 miles & 259.39 & 140.19 & -146.17 & 219.86 \\
Currently married & -4.60 & 159.33 & -269.60 & 273.48 \\
Has at least one child & 41.33 & 130.23 & 746.52 & 254.62 \\
Completed schooling & 78.11 & 40.45 & 8.82 & 38.32 \\
\hline Number of Observations & \multicolumn{4}{|c|}{4932} \\
R-squared & 0.79 & \multicolumn{4}{c}{2639} \\
\hline
\end{tabular}


Table 10

Logit Estimates of the Probability of Receiving a Bequest

Fixed Effects

\begin{tabular}{l|rrr}
\hline & \multicolumn{3}{|c}{ AHEAD } \\
\hline Child's Characteristics: & Coeff & Std Err & Deriv \\
\hline Total Family Income AHEAD & & & \\
Less than $\$ 20,000$ & -0.352 & 0.394 & -0.078 \\
$20,000-30,000$ & 0.639 & 0.348 & 0.152 \\
$30,000-50,000$ & 0.241 & 0.289 & 0.054 \\
greater than 50,000 (omitted) & - & - & - \\
less than 30,000 & -0.716 & 0.743 & -0.159 \\
less than 50,000 & -0.046 & 0.507 & -0.010 \\
greater than 30,000 & -0.667 & 0.450 & -0.149 \\
Total Income missing & -0.491 & 0.388 & -0.109 \\
Age & -0.029 & 0.013 & -0.006 \\
Male & -0.187 & 0.168 & -0.042 \\
Own their own home & -0.239 & 0.231 & -0.053 \\
Live within 10 miles & 0.600 & 0.213 & 0.133 \\
Currently married & -0.240 & 0.227 & -0.053 \\
Has at least one child & 0.155 & 0.248 & 0.034 \\
Completed schooling & 0.132 & 0.045 & 0.029 \\
\hline Number of Observations & \multicolumn{3}{|c}{752} \\
\hline Derivatives are evaluated at the means of the right hand side variables.
\end{tabular}


Appendix A1

Probability Child Receives an Inter Vivos Transfer or Bequest

No Fixed Effects

\begin{tabular}{|c|c|c|c|c|c|c|}
\hline & \multirow{2}{*}{\multicolumn{2}{|c|}{$\begin{array}{c}\text { HRS } \\
\text { inter vivos }\end{array}$}} & \multicolumn{4}{|c|}{ AHEAD } \\
\hline & & & \multicolumn{2}{|c|}{ inter vivos } & \multicolumn{2}{|c|}{ bequests } \\
\hline & Coeff & Std Err & Coeff & Std Err & Coeff & Std Err \\
\hline \multicolumn{7}{|l|}{ Child's Characteristics: } \\
\hline \multicolumn{7}{|l|}{ Total Family Income HRS } \\
\hline Less than $\$ 10,000$ & 0.911 & 0.087 & - & - & - & - \\
\hline $10,000-24,999$ & 0.553 & 0.067 & - & - & - & - \\
\hline 25,000 or more (omitted) & - & - & - & - & - & - \\
\hline \multicolumn{7}{|l|}{ Total Family Income AHEAD } \\
\hline Less than $\$ 20,000$ & - & - & 0.540 & 0.127 & -0.028 & 0.120 \\
\hline $20,000-30,000$ & - & - & 0.483 & 0.110 & 0.066 & 0.101 \\
\hline $30,000-50,000$ & - & - & -0.040 & 0.089 & 0.083 & 0.080 \\
\hline greater than 50,000 (omitted) & - & - & - & - & - & - \\
\hline less than 30,000 & - & - & 0.347 & 0.217 & -0.127 & 0.172 \\
\hline less than 50,000 & - & - & -0.153 & 1.301 & -0.338 & 0.150 \\
\hline greater than 30,000 & - & - & -0.119 & 0.146 & -0.011 & 0.125 \\
\hline Total Income missing & -0.243 & 0.127 & -0.326 & 0.131 & -0.215 & 0.109 \\
\hline Age & -0.062 & 0.006 & -0.017 & 0.005 & -0.007 & 0.004 \\
\hline Male & -0.260 & 0.063 & -0.002 & 0.057 & -0.128 & 0.045 \\
\hline Own their own home & -0.231 & 0.063 & -0.217 & 0.084 & 0.179 & 0.067 \\
\hline Live within 10 miles & 0.163 & 0.054 & 0.186 & 0.062 & 0.071 & 0.057 \\
\hline Currently married & -0.260 & 0.063 & -0.246 & 0.081 & 0.047 & 0.065 \\
\hline Has at least one child & -0.233 & 0.063 & 0.344 & 0.087 & -0.090 & 0.074 \\
\hline Completed schooling & 0.026 & 0.014 & 0.041 & 0.016 & 0.061 & 0.014 \\
\hline \multicolumn{7}{|l|}{ Respondent's characteristics } \\
\hline Age (of male in couple) & 0.009 & 0.005 & 0.007 & 0.005 & -0.017 & 0.004 \\
\hline Highest grade completed (head) & 0.054 & 0.011 & 0.014 & 0.005 & -0.005 & 0.006 \\
\hline \multicolumn{7}{|l|}{ Income quartile } \\
\hline 1st-lowest & -1.014 & 0.122 & -1.652 & -0.713 & 0.152 & \\
\hline 2nd & -0.572 & 0.094 & -1.156 & 0.046 & 0.139 & \\
\hline 3 rd & -0.312 & 0.082 & -0.560 & -0.011 & 0.128 & \\
\hline 4th (omitted) & - & - & - & - & - & - \\
\hline \multicolumn{7}{|l|}{ Wealth quartile } \\
\hline 1st-lowest & -1.101 & 0.115 & -0.978 & 0.171 & -1.338 & 0.145 \\
\hline 2nd & -0.529 & 0.089 & -0.733 & 0.125 & -0.367 & 0.134 \\
\hline 3rd & -0.306 & 0.080 & -0.494 & 0.101 & 0.061 & 0.126 \\
\hline 4th (omitted) & - & - & - & & - & - \\
\hline Taxable estate & 1.433 & 0.420 & 0.527 & 0.357 & 0.057 & 0.552 \\
\hline Prob head lives to age 75 & 0.102 & 0.121 & - & - & - & - \\
\hline Prob head lives $\sim 10$ years & - & - & -0.305 & 0.138 & -0.253 & 0.138 \\
\hline Prob head lives* taxable estate & -1.762 & 0.536 & 0.403 & 0.564 & 0.189 & 0.959 \\
\hline Nonwhite (head) & -0.190 & 0.093 & -0.510 & 0.124 & -1.201 & 0.128 \\
\hline Married & -0.222 & 0.080 & -0.190 & 0.094 & -0.057 & 0.102 \\
\hline Number of living children & -0.233 & 0.020 & -0.305 & 0.032 & -0.109 & 0.022 \\
\hline Resp or spouse in fair or poor health & -0.066 & 0.077 & -0.076 & 0.089 & -0.294 & 0.088 \\
\hline Number of Observations & \multicolumn{2}{|c|}{18,045} & \multicolumn{2}{|c|}{18045} & \multicolumn{2}{|c|}{11,185} \\
\hline
\end{tabular}


Appendix A2

Amount of Inter Vivos Transfer

No Fixed Effects

\begin{tabular}{|c|c|c|c|c|}
\hline & \multicolumn{2}{|c|}{ HRS } & \multicolumn{2}{|c|}{ AHEAD } \\
\hline & Coeff & Std Ert & Coeff & Std Err \\
\hline \multicolumn{5}{|l|}{ Child's Characteristics: } \\
\hline \multicolumn{5}{|l|}{ Total Family Income HRS } \\
\hline Less than $\$ 10,000$ & 1144.07 & 220.81 & - & - \\
\hline $10,000-24,999$ & 511.57 & 211.54 & - & - \\
\hline 25,000 or more (omitted) & - & - & - & - \\
\hline \multicolumn{5}{|l|}{ Total Family lncome AHEAD } \\
\hline Less than $\$ 20,000$ & - & - & 71.81 & 105.20 \\
\hline $20,000-30,000$ & - & - & 179.76 & 190.82 \\
\hline $30,000-50,000$ & - & - & -56.13 & 104.20 \\
\hline greater than 50,000 (omitted) & - & - & - & - \\
\hline less than 30,000 & - & - & -45.84 & 108.21 \\
\hline less than 50,000 & - & - & -39.05 & 123.94 \\
\hline greater than 30,000 & - & - & -146.09 & 119.49 \\
\hline Total Income missing & 402.23 & 211.85 & 170.88 & 101.64 \\
\hline Age & -59.39 & 16.76 & -5.75 & 2.91 \\
\hline Male & 187.15 & 145.67 & 9.35 & 39.97 \\
\hline Own their own home & 428.77 & 176.98 & 82.82 & 87.77 \\
\hline Live within 10 miles & 229.99 & 122.29 & 3.92 & 50.29 \\
\hline Currently married & -56.85 & 124.42 & 254.27 & 121.93 \\
\hline Has at least one child & -75.34 & 161.99 & 87.14 & 62.85 \\
\hline Completed schooling & 215.14 & 59.02 & 34.49 & 11.87 \\
\hline \multicolumn{5}{|l|}{ Respondent's characteristics } \\
\hline Age (of male in couple) & 10.49 & 6.22 & 17.26 & 7.06 \\
\hline Highest grade completed (head) & 12.59 & 7.09 & 6.52 & 3.45 \\
\hline \multicolumn{5}{|l|}{ Income quartile } \\
\hline 1st-lowest & -221.89 & 315.72 & -681.11 & 125.04 \\
\hline 2nd & -137.11 & 237.55 & -699.01 & 111.07 \\
\hline 3rd & -7.83 & 304.91 & -631.01 & 105.23 \\
\hline 4th (omitted) & - & - & - & - \\
\hline \multicolumn{5}{|l|}{ Wealth quartile } \\
\hline 1st-lowest & -631.28 & 417.35 & -209.19 & 113.94 \\
\hline 2nd & -941.77 & 178.78 & -258.81 & 89.44 \\
\hline 3rd & -829.39 & 190.54 & -222.38 & 101.81 \\
\hline 4th (omitted) & - & - & - & - \\
\hline Taxable estate & 1916.90 & 856.99 & 4429.97 & 3013.72 \\
\hline Prob head lives to age 75 & 162.40 & 77.57 & - & - \\
\hline Prob head lives $\sim 10$ years & - & - & -169.62 & 102.85 \\
\hline Prob head lives * taxable estate & -1817.31 & 998.86 & -2595.30 & 3057.68 \\
\hline Nonwhite (head) & -107.24 & 43.84 & 0.89 & 55.96 \\
\hline Married & -6.3 .71 & 51.35 & 5.13 & 114.64 \\
\hline Number of living children & -60.10 & 8.24 & -65.56 & 13.52 \\
\hline Resp or spouse in fair or poor health & 16.95 & 46.07 & -3.99 & 75.53 \\
\hline Number of Observations & \multicolumn{2}{|c|}{17999} & \multicolumn{2}{|c|}{13196} \\
\hline R-squared & \multicolumn{2}{|c|}{0.04} & \multicolumn{2}{|c|}{0.06} \\
\hline
\end{tabular}


Table A3

Amount of Inter Vivos Transfer

No Fixed Effects and Excluding Transfers $\geq 10,000$

\begin{tabular}{|c|c|c|c|c|}
\hline & \multicolumn{2}{|c|}{ HRS } & \multicolumn{2}{|c|}{ AHEAD } \\
\hline & Coeff & Std Err & Coeff & td Err \\
\hline \multicolumn{5}{|l|}{ Child's Characteristics: } \\
\hline \multicolumn{5}{|l|}{ Total Family Income HRS } \\
\hline Less than $\$ 10,000$ & 267.2 & 22.6 & - & - \\
\hline $10,000-24,999$ & 139.7 & 17.0 & - & - \\
\hline 25,000 or more (omitted) & - & - & - & - \\
\hline \multicolumn{5}{|l|}{ Total Family Income AHEAD } \\
\hline Less than $\$ 20,000$ & - & - & 133.7 & 29.4 \\
\hline $20,000-30,000$ & - & - & 81.0 & 26.6 \\
\hline $30,000-50,000$ & - & - & 25.2 & 21.3 \\
\hline greater than 50,000 (omitted) & - & - & - & - \\
\hline less than 30,000 & - & - & 65.3 & 49.9 \\
\hline less than 50,000 & - & - & -3.5 & 38.6 \\
\hline greater than 30,000 & - & - & -53.3 & 33.5 \\
\hline Total Income missing & 33.6 & 21.2 & -30.8 & 23.1 \\
\hline Number of Observations & \multicolumn{2}{|c|}{17851} & \multicolumn{2}{|c|}{13017} \\
\hline R-squared & \multicolumn{2}{|c|}{0.07} & \multicolumn{2}{|c|}{0.08} \\
\hline
\end{tabular}

